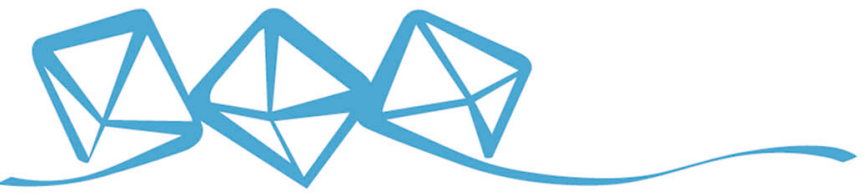 COMMUNICATIONS MATERIALS
}

ARTICLE

https://doi.org/10.1038/s43246-020-0023-4

OPEN

\section{Photovoltaic organic interface for neuronal stimulation in the near-infrared}

Marta Jole Ildelfonsa Airaghi Leccardi (10 1, Naïg Aurelia Ludmilla Chenais', Laura Ferlauto1, Maciej Kawecki (i) 2,3, Elodie Geneviève Zollinger ${ }^{1} \&$ Diego Ghezzi (iD) ${ }^{1 凶}$

Organic materials, such as conjugated polymers, are attractive building blocks for bioelectronic interfaces. In particular, organic semiconductors show excellent performance in lightmediated excitation and silencing of neuronal cells and tissues. However, the main challenges of these organic photovoltaic interfaces compared to inorganic prostheses are the limited adhesion of conjugated polymers in aqueous environments and the exploitation of materials responsive in the visible spectrum. Here, we show a photovoltaic organic interface optimized for neuronal stimulation in the near-infrared spectrum. We adjusted the organic materials by chemical modification in order to improve the adhesion in an aqueous environment and to modulate the photoelectrical stimulation efficiency. As proof-of-principle, we tested this interface on explanted degenerated mice retinas, thus providing results on the efficiency and reliability of the device as an implant for neural stimulation.

\footnotetext{
${ }^{1}$ Medtronic Chair in Neuroengineering, Center for Neuroprosthetics and Institute of Bioengineering, School of Engineering, École polytechnique fédérale de Lausanne, 1202 Geneva, Switzerland. ${ }^{2}$ Laboratory for Nanoscale Materials Science, Empa 8600 Dübendorf, Switzerland. ${ }^{3}$ Department of Physics, University of Basel, 4056 Basel, Switzerland. ${ }_{\text {email: diego.ghezzi@epfl.ch }}$
} 
O rganic technology has proven to be an efficient tool in bioelectronic interfaces and neuroprostheses for neuronal activity modulation by converting light pulses into electrical or thermal stimulation ${ }^{1-13}$. Flexibility, lightweight and biocompatibility are among the main advantages of using organic technology in bioelectronic interfaces. Nevertheless, compared to their inorganic counterparts (e.g. silicon), some challenges about functional organic materials remain open. First, water-induced swelling, degradation and delamination are among the most critical aspects of organic interfaces implanted into the body. Second, in the case of photovoltaic interfaces, the electrical properties of the photovoltaic cell must be tailored to meet the desired conditions of electrical stimulation. Last, organic semiconductors used in photovoltaic bioelectronic interfaces typically have low photoconversion efficiency, and high sensitivity only in the visible spectrum. However, the use of near-infrared (NIR) light would be preferable in bioelectronic interfaces: for example, because of its higher penetration into the tissue.

A notable example of the use of organic technology in bioelectronic interfaces is the exploitation of conjugated polymers in photovoltaic retinal prostheses, which were proposed to induce artificial vision in blind patients ${ }^{5,14-17}$. Since photovoltaic retinal prostheses wirelessly convert the light entering the pupil into electrical stimuli, they act as artificial photoreceptors to activate surviving retinal cells. In the past years, conjugated polymers (i.e. poly(3,4-ethylenedioxythiophene)-poly(styrenesulfonate), PEDOT: PSS; regioregular poly(3-hexylthiophene-2,5-diyl), P3HT) and other organic semiconductors ([6,6]-phenyl-C61-butyric acid methyl ester, $\left.\mathrm{PC}_{60} \mathrm{BM}\right)$ were successfully exploited to build an organic photovoltaic subretinal interface able to improve visual acuity in dystrophic rats $5,7,15,18,19$. More recently, our group described a novel foldable and photovoltaic wide-field epiretinal prosthesis (POLYRETINA) based on the P3HT:PC ${ }_{60} \mathrm{BM}$ bulk heterojunction $(\mathrm{BHJ})$, with the capability to activate retinal ganglion cells with short pulses of green light ${ }^{14}$. In the recent years, several organic photovoltaic retinal prostheses were developed based on PEDOT:PSS and P3HT:PC ${ }_{60} \mathrm{BM} \mathrm{BHJ}$; however, this $\mathrm{BHJ}$ system might not be the optimal choice for photovoltaic retinal stimulation, because of its absorption spectrum limited to the visible range.

In humans and primates, colour vision is based on three types of opsins associated to three different cones: the short (S-), the medium (M-) and the long (L-) wavelength sensitive cones having distinct but overlapping absorption spectra (Fig. 1a) ${ }^{20}$. The L-cone has the most red-shifted spectral absorbance with a maximum around $564 \mathrm{~nm}$ (Fig. 1a, circles). The absorbance spectra of the $\mathrm{P} 3 \mathrm{HT}: \mathrm{PC}_{60} \mathrm{BM} \mathrm{BHJ}$ and the retinal photoreceptors largely overlap; thus, the green light used to excite the $\mathrm{P} 3 \mathrm{HT}$ : $\mathrm{PC}_{60} \mathrm{BM} \mathrm{BHJ}$ may not be optimal due to the possible activation of remaining cones and rods in patients with residual natural vision, such as in age-related macular degeneration. Moreover, the irradiance levels typically required to stimulate retinal neurons with photovoltaic prostheses (hundreds of $\mu \mathrm{W} \mathrm{mm}{ }^{-2}$ ) may still be perceived (when visible light is used) even in blind patients without residual vision. NIR illumination activates photovoltaic retinal prostheses without interfering with the residual natural vision. Also, according to the standard for optical safety, the maximum permissible exposure (MPE) for ophthalmic applications increases in the NIR spectrum ${ }^{21}$.

In this article, we demonstrate that implantable stimulating devices based on conjugated polymers can operate in the NIR spectrum (i.e. wavelength longer than $700 \mathrm{~nm}$ ). We also document the relevance of the electrical and adhesive properties of the conjugated polymers in the fabrication of a photovoltaic implant with optimised photovoltaic characteristics to achieve an efficient neural stimulation. As proof-of-principle, we designed an organic photovoltaic interface for retinal stimulation, based on the poly [2,6-(4,4-bis-(2-ethylhexyl)-4H-cyclopenta $\quad\left[2,1-b ; 3,4-b^{\prime}\right]$ dithiophene)-alt-4,7(2,1,3-benzothiadiazole)] blended with $\mathrm{PC}_{60} \mathrm{BM}$ (PCPDTBT: $\left.\mathrm{PC}_{60} \mathrm{BM}\right) \mathrm{BHJ}^{1,22}$. We demonstrate that this $\mathrm{BHJ}$ can generate electrical responses at safe irradiance levels suitable for retinal stimulation. Furthermore, we investigate the impact of a cross-linking molecule on adhesive properties and morphology of the organic interface. Last, we also verify that this $\mathrm{BHJ}$ is not
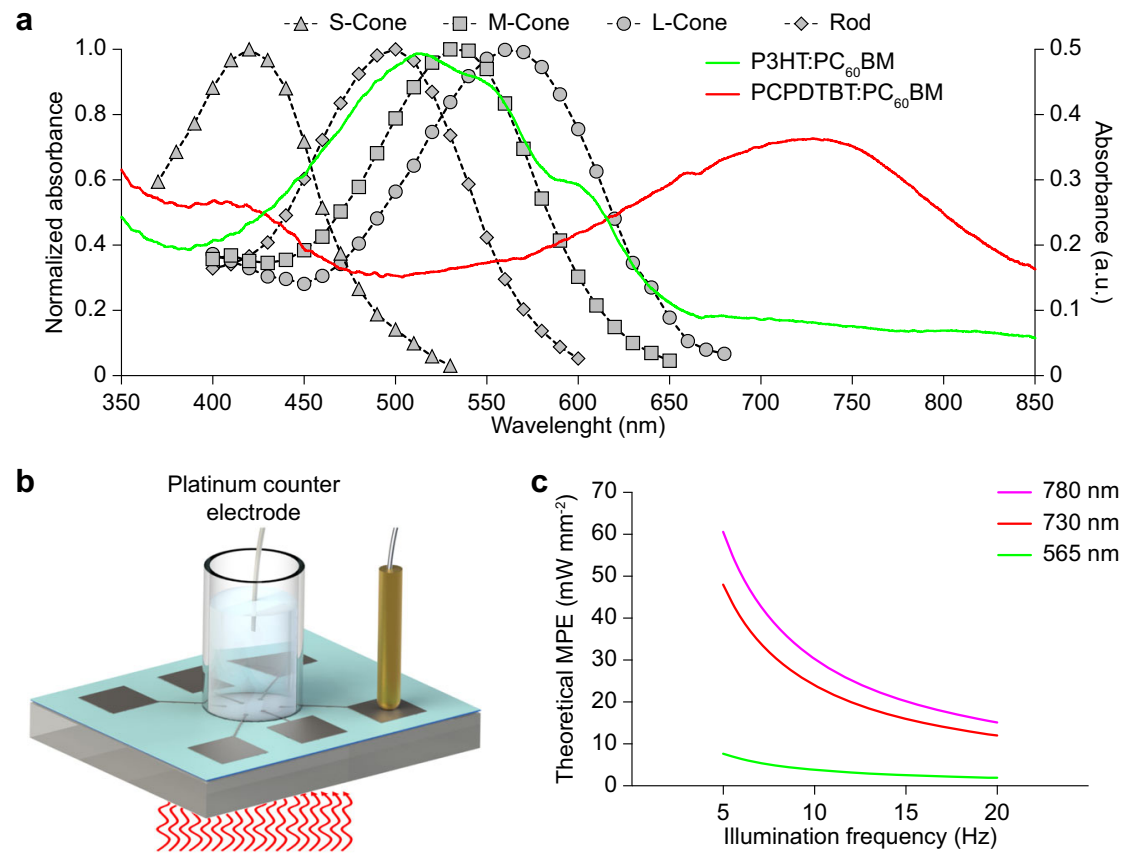

Fig. 1 Relevance of NIR illumination for organic photovoltaic retinal prostheses. a Normalized absorbance spectra of S-cones, M-cones, L-cones and rods on the left axis (redrawn from ref. ${ }^{20}$ ). Absorbance spectra of the P3HT:PC ${ }_{60} B M$ and the PCPDTBT:PC ${ }_{60} B M$ BHJs on the right axis. $\mathbf{b}$ Sketch of the PC and $\mathrm{PV}$ recording setup. c Theoretical MPEs for $10-\mathrm{ms}$ pulses as a function of the illumination rate. 

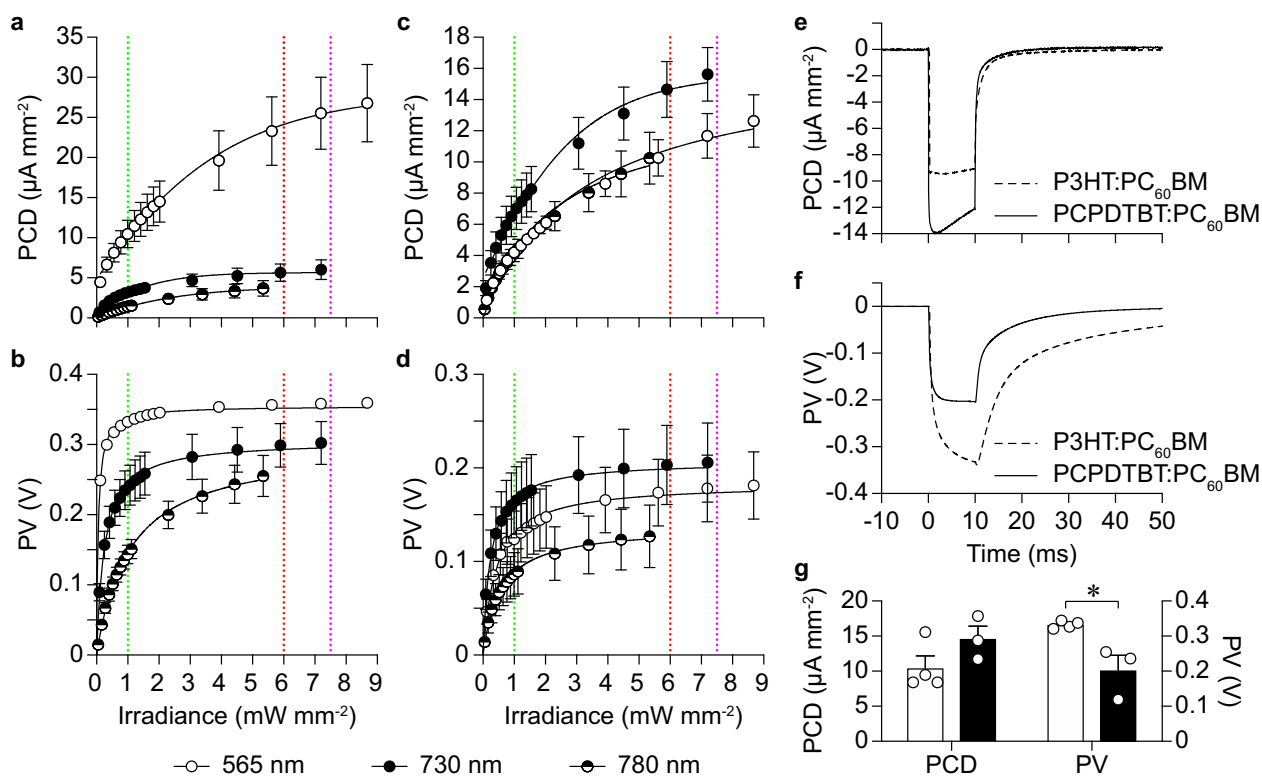

Fig. 2 Optimization of the bulk heterojunction. a, b Mean ( \pm s.e.m., $n=4$ chips) PCD (a) and PV (b) with HTL/P3HT:PC 60 BM/Ti. c, d Mean ( \pm s.e.m., $n=3$

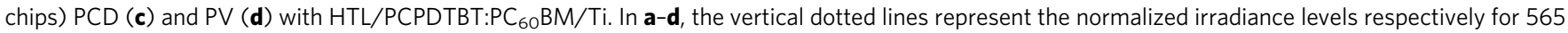
$\mathrm{nm}$ (green, $1 \mathrm{~mW} \mathrm{~mm}^{-2}$ ), $730 \mathrm{~nm}$ (red, $6 \mathrm{~mW} \mathrm{~mm}^{-2}$ ), and $780 \mathrm{~nm}$ (magenta, $7.5 \mathrm{~mW} \mathrm{~mm}^{-2}$ ). The solid lines are the interpolations with an asymmetrical, five-parameter, logistic dose-response function for PCDs and a hyperbola function for PVs. e, f Grand-average PCD (e) and PV (f) traces with HTL/P3HT: $\mathrm{PC}_{60} \mathrm{BM} / \mathrm{Ti}$ (dashed line, $565 \mathrm{~nm}, n=4$ chips) and HTL/PCPDTBT:PC ${ }_{60} \mathrm{BM} / \mathrm{Ti}$ (solid line, $730 \mathrm{~nm}, n=3$ chips) BHJs respectively at their normalized irradiance levels. g, Mean ( \pm s.e.m.) PCD and PV obtained with HTL/P3HT:PC ${ }_{60} \mathrm{BM} / \mathrm{Ti}$ (white bars, $565 \mathrm{~nm}, n=4$ chips) and HTL/PCPDTBT:PC 60 BM/Ti (black bars, $730 \mathrm{~nm}, n=3$ chips) respectively at their normalized irradiance levels.

cytotoxic. These results enable the development of a NIRsensitive foldable and photovoltaic wide-field epiretinal prosthesis, here called nirPOLYRETINA.

\section{Results}

Optimization of the bulk heterojunction. To evaluate the performance of the BHJs in the NIR spectrum, we fabricated chips embedding six photovoltaic pixels, each composed of three layers: an anode made of PEDOT:PSS (HTL Solar), the BHJ (P3HT: $\mathrm{PC}_{60} \mathrm{BM}$ or PCPDTBT: $\left.\mathrm{PC}_{60} \mathrm{BM}\right)$, and a cathode made of titanium (Ti). The cathode of each photovoltaic pixel was contacted to measure its output signal referenced to a platinum counter electrode immersed in saline solution (Fig. 1b). We measured the responses of photovoltaic pixels based on both BHJs upon 10-ms light pulses at two NIR wavelengths (730 and $780 \mathrm{~nm}$, where the response of cones should be minimal) and compared them to the ones obtained upon green light illumination $(565 \mathrm{~nm})$. In all the experiments, for each chip, the responses from the six electrodes were measured, and the peak amplitudes were quantified and averaged.

As expected, the $\mathrm{P} 3 \mathrm{HT}: \mathrm{PC}_{60} \mathrm{BM} \mathrm{BHJ}$ showed the strongest photo-current density (PCD) at $565 \mathrm{~nm}$ (Fig. 2a, white circles). However, to evaluate the responsivity at the three wavelengths, we should take into account the theoretical MPE for each wavelength, which is dependent on the pulse duration, the illumination rate, and the angle of illumination (fixed to $46.3^{\circ}$, according to the design of the POLYRETINA device ${ }^{14}$ ). For chronic illumination, the MPEs are $384.75 \mu \mathrm{W} \mathrm{mm} \mathrm{m}^{-2}, 2.40 \mathrm{~mW} \mathrm{~mm}^{-2}$ and $3.03 \mathrm{~mW} \mathrm{~mm}^{-2}$, respectively for 565,730 and $780 \mathrm{~nm}$. In case of $10-\mathrm{ms}$ pulsed illumination (Fig. 1c), the theoretical MPE is increased by a factor of 5 for $20 \mathrm{~Hz}$ repetition rate $\left(1.92,12.00\right.$ and $15.15 \mathrm{~mW} \mathrm{~mm}^{-2}$ respectively for 565,730 and $780 \mathrm{~nm}$ ), by a factor of 10 for $10 \mathrm{~Hz}$ repetition rate $\left(3.85,24.00\right.$, and $30.30 \mathrm{~mW} \mathrm{~mm}^{-2}$, respectively for 565,730 and $780 \mathrm{~nm}$ ), and by a factor of 20 for $5 \mathrm{~Hz}$ repetition rate
(7.70, 48.00, and $60.60 \mathrm{~mW} \mathrm{~mm}^{-2}$ respectively for 565,730 and $780 \mathrm{~nm}$ ). Therefore, we set the irradiance levels to the following normalized values: 1,6 , and $7.5 \mathrm{~mW} \mathrm{~mm}^{-2}$, respectively for 565 , 730 and $780 \mathrm{~nm}$. These normalized irradiance levels correspond to $\sim 50 \%$ of the theoretical MPEs at $20 \mathrm{~Hz}, 25 \%$ at $10 \mathrm{~Hz}$ and $12.5 \%$ at $5 \mathrm{~Hz}$.

For the P3HT:PC ${ }_{60} \mathrm{BM}$ BHJ, the mean PCD obtained at $565 \mathrm{~nm}$ with pulses of $1 \mathrm{~mW} \mathrm{~mm}^{-2}$ (white circles, green line) is 1.85 times higher than the mean PCD obtained at $730 \mathrm{~nm}$ (black circles, red line) with pulses of $6 \mathrm{~mW} \mathrm{~mm}^{-2}$ (Fig. 2a). At $780 \mathrm{~nm}$ (black/white circles) the maximal irradiance obtained from the LED was $5.35 \mathrm{~mW} \mathrm{~mm}^{-2}$, which is lower than the normalized irradiance $\left(7.5 \mathrm{~mW} \mathrm{~mm}^{-2}\right)$. Therefore, the theoretical PCD value was computed using the interpolating curve $\left(R^{2}=0.74\right)$. In both cases (730 and $780 \mathrm{~nm})$, the PCD obtained at the normalized irradiance levels is largely lower than the one obtained with a green light $(565 \mathrm{~nm})$. The photo-voltage (PV) had a similar behaviour (Fig. 2b). The theoretical PV at $780 \mathrm{~nm}$ and $7.5 \mathrm{~mW}$ $\mathrm{mm}^{-2}$ (black/white circles, magenta line) was computed using the interpolating curve $\left(R^{2}=0.91\right)$. Based on these results, we decided to investigate a different $\mathrm{BHJ}$ based on the PCPDTBT: $\mathrm{PC}_{60} \mathrm{BM}$ blend, which might be more efficient for a NIRresponsive retinal prosthesis.

In this case, the wavelength with the highest PCD (Fig. 2c) and PV (Fig. 2d) is $730 \mathrm{~nm}$ (black circles). Moreover, if compared at the normalized irradiance levels, the PCD obtained at $730 \mathrm{~nm}$ with HTL/PCPDTBT:PC ${ }_{60} \mathrm{BM} / \mathrm{Ti}$ is 1.4 times higher than the PCD obtained at $565 \mathrm{~nm}$ with HTL/P3HT:PC ${ }_{60} \mathrm{BM} / \mathrm{Ti}$ (Fig. 2e, g; two-tailed $t$-test, $p=0.1571)$. On the other hand, the $\mathrm{PV}$ is slightly lower (Fig. 2f, g; two-tailed $t$-test, $p=0.0158$ ). These results suggest that the PCPDTBT:PC ${ }_{60} \mathrm{BM} \mathrm{BHJ} \mathrm{(at} 730 \mathrm{~nm}$ ) should be as efficient as the P3HT:PC ${ }_{60} \mathrm{BM}$ blend (at $565 \mathrm{~nm}$ ) previously used in the POLYRETINA device, considering irradiance levels adjusted to their respective theoretical MPEs. Also, as well as HTL/P3HT:PC ${ }_{60} \mathrm{BM} / \mathrm{Ti}$ pixels, the photovoltaic 

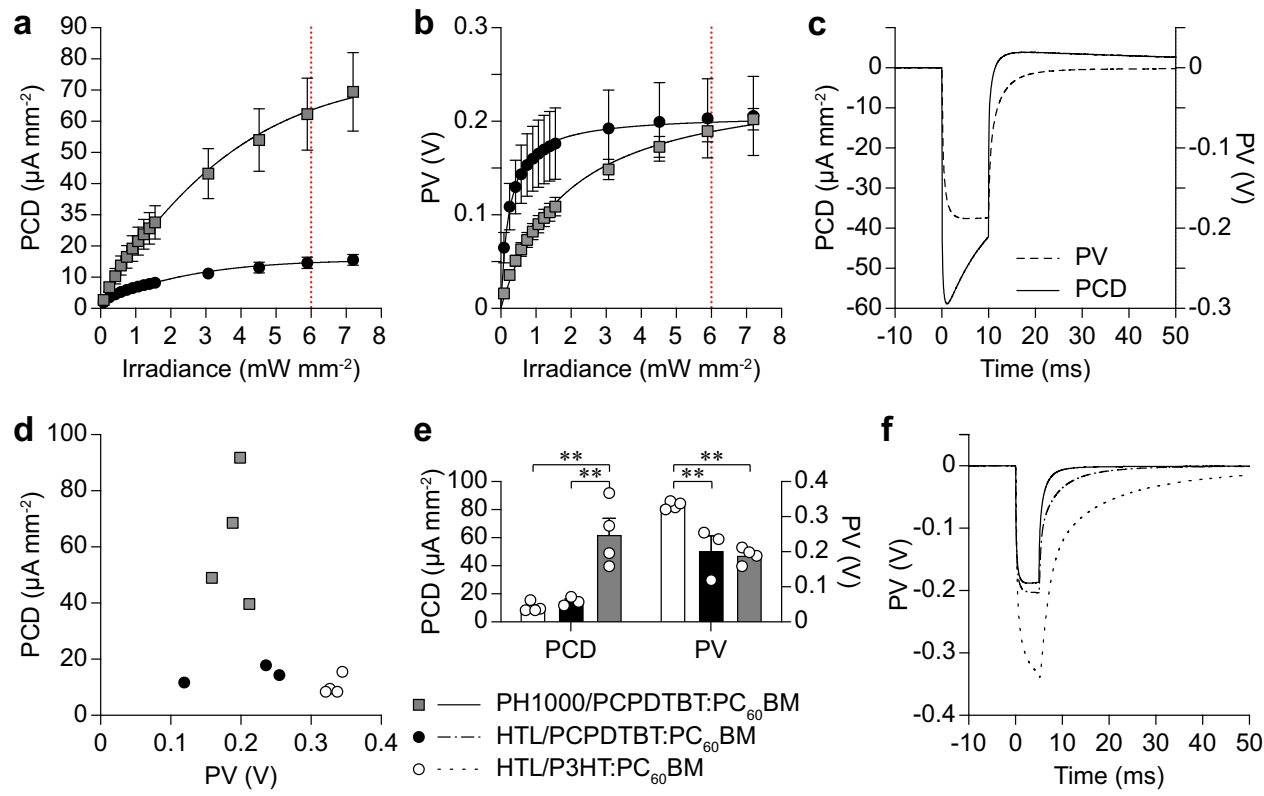

Fig. 3 Optimization of the anodic layer. a, b Mean ( \pm s.e.m.) PCD (a) and PV (b) obtained at $730 \mathrm{~nm}$ for HTL/PCPDTBT:PC ${ }_{60} B M / T i(b l a c k$ circles, $n=3$ chips) and PH1000/PCPDTBT:PC 60 BM/Ti (grey squares, $n=4$ chips). The solid lines are the interpolations with an asymmetrical, five-parameter, logistic dose-response function for PCDs and a hyperbola function for PVs. The vertical red dotted lines represent the normalized irradiance for $730 \mathrm{~nm}$ ( $6 \mathrm{~mW}$ $\mathrm{mm}^{-2}$ ). c, Grand-average PCD (solid line) and PV (dashed line) traces obtained with PH1000/PCPDTBT:PC 60 BM/Ti with $730 \mathrm{~nm}$ at the normalized irradiance ( $n=4$ chips). d, PV/PCD plot for HTL/P3HT:PC ${ }_{60} B M / T i$ (white circles, $n=4$ chips, $565 \mathrm{~nm}, 1 \mathrm{~mW} \mathrm{~mm}^{-2}$ ), HTL/PCPDTBT:PC 60 BM/Ti (black circles, $n=3$ chips, $730 \mathrm{~nm}, 6 \mathrm{~mW} \mathrm{~mm}^{-2}$ ), and PH1000/PCPDTBT:PC 60 BM/Ti (grey squares, $n=4$ chips, $730 \mathrm{~nm}, 6 \mathrm{~mW} \mathrm{~mm}^{-2}$ ). e Mean ( \pm s.e.m.) PCD and PV obtained with HTL/P3HT:PC ${ }_{60} B M / T i$ (white bars, $10.46 \pm 1.72 \mu \mathrm{Amm}^{-2}, 332.5 \pm 5.35 \mathrm{mV}, n=4 \mathrm{chips}, 565 \mathrm{~nm}, 1 \mathrm{~mW} \mathrm{~mm}^{-2}$ ), HTL/PCPDTBT: $\mathrm{PC}_{60} \mathrm{BM} / \mathrm{Ti}$ (black bars, $14.65 \pm 1.79 \mu \mathrm{A} \mathrm{mm} \mathrm{m}^{-2}, 203.4 \pm 42.37 \mathrm{mV}, n=3$ chips, $730 \mathrm{~nm}, 6 \mathrm{~mW} \mathrm{~mm}^{-2}$ ), and PH1000/PCPDTBT:PC ${ }_{60} \mathrm{BM}_{/ T i}$ (grey bars, $62.28 \pm 11.54 \mu \mathrm{A} \mathrm{mm}^{-2}, 189.6 \pm 11.32 \mathrm{mV}, \mathrm{n}=4$ chips, $730 \mathrm{~nm}, 6 \mathrm{~mW} \mathrm{~mm}^{-2}$ ), respectively, at their normalized irradiance levels. $\mathbf{f}$ Comparison of the PV grand-average traces for HTL/P3HT:PC ${ }_{60} \mathrm{BM} / \mathrm{Ti}$ (dotted line, $n=4$ chips, $565 \mathrm{~nm}, 1 \mathrm{~mW} \mathrm{~mm}{ }^{-2}$ ), HTL/PCPDTBT:PC ${ }_{60} \mathrm{BM} \mathrm{Ti}$ (dashed-dotted line, $n=3$ chips, $730 \mathrm{~nm}, 6 \mathrm{~mW} \mathrm{~mm}^{-2}$ ), and PH1000/PCPDTBT:PC 60 BM/Ti (solid line, $n=4$ chips, $730 \mathrm{~nm}, 6 \mathrm{~mW} \mathrm{~mm}^{-2}$ ).

electrodes based on the PCPDTBT:PC ${ }_{60} \mathrm{BM} \mathrm{BHJ}$ are fully discharged in $<40 \mathrm{~ms}$ from the pulse offset (Fig. 2f), allowing a stimulation pulse rate up to $20 \mathrm{~Hz}$.

Optoelectronic optimization of the anodic layer. Photovoltaic organic retinal prostheses typically rely on a bottom anode made of PEDOT:PSS $5,14-16,18$. We therefore investigated the optoelectronic effect of its conductivity by using two formulations from Clevios Heraeus: HTL Solar $\left(0.47 \mathrm{~S} \mathrm{~mm}^{-1}\right.$, average of 5 measures from 1 sample; film thickness of $60 \mathrm{~nm})$ and PH1000 $\left(1.17 \mathrm{~S} \mathrm{~mm}^{-1}\right.$, average of 5 measures from 1 sample; film thickness of $90 \mathrm{~nm})$. At $730 \mathrm{~nm}$, the mean PCD obtained with the PH1000/PCPDTBT: $\mathrm{PC}_{60} \mathrm{BM} / \mathrm{Ti}$ pixel (grey squares) is considerably higher than the HTL/PCPDTBT:PC ${ }_{60} \mathrm{BM} / \mathrm{Ti}$ pixel (black circles), while the mean $\mathrm{PV}$ increases with a lower rate but it reaches the same value at the normalized irradiance for $730 \mathrm{~nm}$ (Fig. 3a, b). To summarize our findings (Fig. $3 \mathrm{~d}, \mathrm{e}$ ), the PV and PCD values obtained with the three configurations presented were compared at their best operational wavelengths $(565 \mathrm{~nm}$ for $\mathrm{P} 3 \mathrm{HT}$ and $730 \mathrm{~nm}$ for PCPDTBT $)$ and at the normalized irradiance levels $\left(1 \mathrm{~mW} \mathrm{~mm}^{-2}\right.$ for $565 \mathrm{~nm}$ and $6 \mathrm{~mW} \mathrm{~mm}^{-2}$ for $730 \mathrm{~nm}$ ). The PH1000/ PCPDTBT:PC ${ }_{60} \mathrm{BM} / \mathrm{Ti}$ pixels (grey squares) showed the highest PCD (one-way ANOVA, $p=0.0018, F=15.48$; Tuckey's multiple comparisons test: HTL/P3HT:PC ${ }_{60} \mathrm{BM} / \mathrm{Ti}$ vs HTL/PCPDTBT: $\mathrm{PC}_{60} \mathrm{BM} / \mathrm{Ti} \quad p=0.9235, \mathrm{HTL} / \mathrm{P} 3 \mathrm{HT}: \mathrm{PC}_{60} \mathrm{BM} / \mathrm{Ti}$ vs $\mathrm{PH} 1000 /$ PCPDTBT:PC ${ }_{60} \mathrm{BM} / \mathrm{Ti} p=0.0024, \mathrm{HTL} / \mathrm{PCPDTBT}: \mathrm{PC}_{60} \mathrm{BM} / \mathrm{Ti}$ vs PH1000/PCPDTBT:PC $\left.{ }_{60} \mathrm{BM} / \mathrm{Ti} p=0.0062\right)$. On the other hand, the HTL/P3HT:PC ${ }_{60} \mathrm{BM} / \mathrm{Ti}$ pixels (white circles) showed the highest PV (one-way ANOVA, $p=0.0019, \quad F=15.21$; Tuckey's multiple comparisons test: HTL/P3HT:PC ${ }_{60} \mathrm{BM} / \mathrm{Ti}$ vs HTL/PCPDTBT:PC ${ }_{60} \mathrm{BM} / \mathrm{Ti} p=0.0070$, HTL/P3HT:PC ${ }_{60} \mathrm{BM} / \mathrm{Ti}$ vs $\mathrm{PH} 1000 / \mathrm{PCPDTBT}: \mathrm{PC}_{60} \mathrm{BM} / \mathrm{Ti} p=0.0024, \mathrm{HTL} / \mathrm{PCPDTBT}$ : $\mathrm{PC}_{60} \mathrm{BM} / \mathrm{Ti}$ vs $\left.\mathrm{PH} 1000 / \mathrm{PCPDTBT}: \mathrm{PC}_{60} \mathrm{BM} / \mathrm{Ti} p=0.8937\right)$. The HTL/PCPDTBT:PC ${ }_{60} \mathrm{BM} / \mathrm{Ti}$ pixels (black circles) showed the lowest PCD and PV. Interestingly, the different configurations also have different photovoltage discharge rates at the offset of the light pulse (Fig. 3f). The PH1000/PCPDTBT:PC ${ }_{60} \mathrm{BM} / \mathrm{Ti}$ pixel showed the faster discharge rate, probably because of the higher electrical conductivity of PH1000 (two-phase exponential decay; $\mathrm{HTL} / \mathrm{P} 3 \mathrm{HT}: \mathrm{PC}_{60} \mathrm{BM} / \mathrm{Ti}: \tau_{\text {fast }}=4.59 \mathrm{~ms}$ and $\tau_{\text {slow }}=33.36 \mathrm{~ms}$, $R^{2}=0.93 ; \quad$ HTL/PCPDTBT:PC ${ }_{60} \mathrm{BM} / \mathrm{Ti}: \quad \tau_{\text {fast }}=1.03 \mathrm{~ms}$ and $\tau_{\text {slow }}=11.31 \mathrm{~ms}, \quad R^{2}=0.95 ; \quad \mathrm{PH} 1000 / \mathrm{PCPDTBT}: \mathrm{PC}_{60} \mathrm{BM} / \mathrm{Ti}:$ $\tau_{\text {fast }}=0.47 \mathrm{~ms}$ and $\tau_{\text {slow }}=3.58 \mathrm{~ms}, R^{2}=0.82$ ).

Optimization of the anodic layer adhesion. Strong adhesion between materials is a prerequisite for the long-term functioning of an implantable device. However, in organic-based prostheses, the adhesion of the PEDOT:PSS layer over a substrate in aqueous environment is limited by the delamination and solubility of PSS. A common strategy to obtain water-stable thin films of PEDOT: PSS is to add the (3-glycidyloxypropyl)trimethoxysilane (GOPS) crosslinker (typically $1 \mathrm{v} / \mathrm{v} \%$ ), which prevents both dissolution and delamination of PEDOT:PSS films ${ }^{23}$. On the other hand, it was reported that the electrical conductivity of PEDOT:PSS films decreases as a function of the GOPS content ${ }^{23,24}$. We found that the addition of $1 \mathrm{v} / \mathrm{v} \%$ of GOPS to $\mathrm{PH} 1000$ reduces the PCD (Fig. $4 \mathrm{a}, \mathrm{c}$ ) and increases the PV (Fig. 4b, d) generated by the $\mathrm{PH} 1000 / \mathrm{PCPDTBT}: \mathrm{PC}_{60} \mathrm{BM} / \mathrm{Ti}$ pixels at $730 \mathrm{~nm}$. Moreover, it causes a very slow photovoltage discharge (two-phase exponential decay, $\tau_{\text {fast }}=11.21 \mathrm{~ms}$ and $\left.\tau_{\text {slow }}=72.52 \mathrm{~ms}, R^{2}=0.96\right)$. Indeed, such configuration does not allow a full discharge and recharge of the electrode voltage between each pulse during $20 \mathrm{~Hz}$ train 

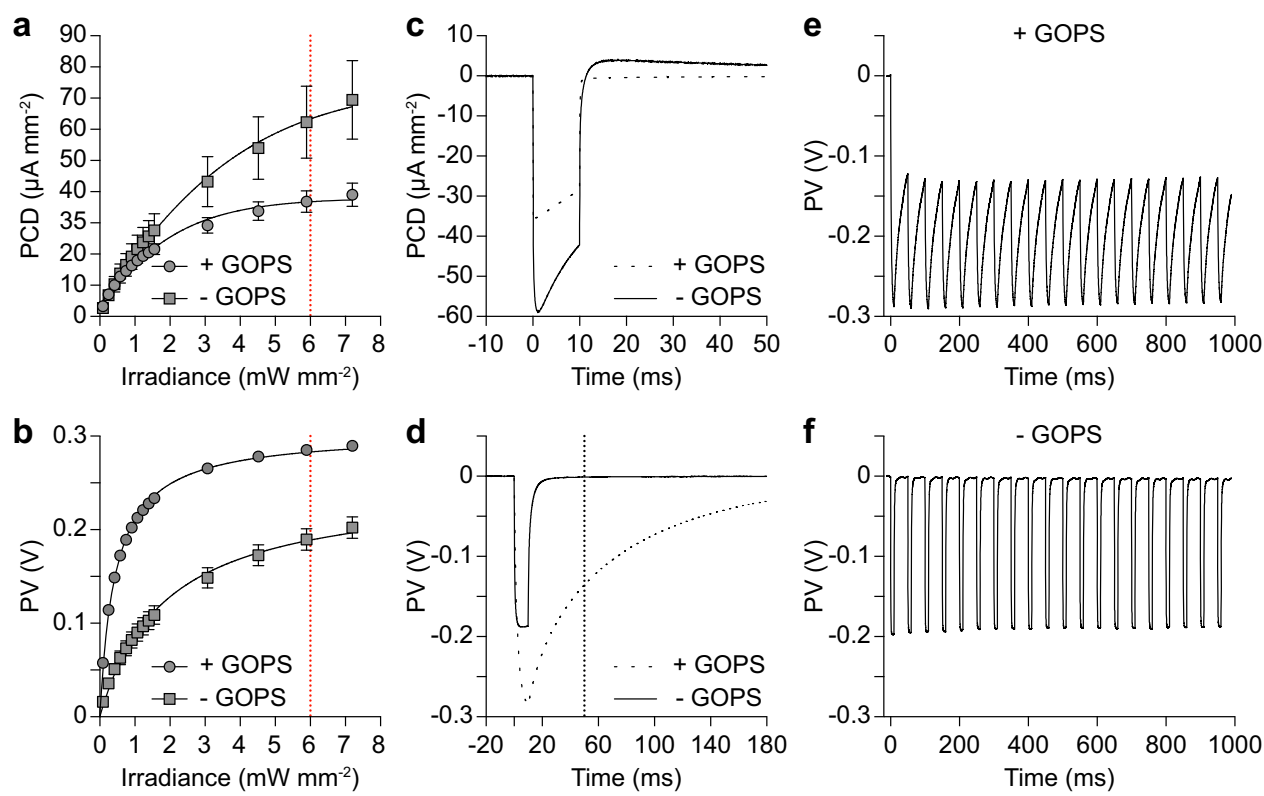

Fig. 4 Optoelectronic responses with GOPS. a, b Mean ( \pm s.e.m.) PCD (a) and PV (b) obtained with pristine PH1000/PCPDTBT:PC 60 BM/Ti (grey squares, $n=4$ ) and PH1000/PCPDTBT:PC ${ }_{60}$ BM/Ti supplemented with $1 \mathrm{v} / \mathrm{v} \%$ GOPS (grey circles, $n=3$ ) at $730 \mathrm{~nm}$. The solid lines are the interpolations with an asymmetrical, five-parameter, logistic dose-response function for PCDs and a hyperbola function for PVs. The vertical red dotted lines represent the normalized irradiance for $730 \mathrm{~nm}\left(6 \mathrm{~mW} \mathrm{~mm}^{-2}\right)$. c, d Grand-average PCD (c) and PV (d) traces obtained upon 10-ms pulses $\left(730 \mathrm{~nm}, 6 \mathrm{~mW}\right.$ mm $\left.{ }^{-2}\right)$ with pristine PH1000 (solid line, $n=4$ ) and PH1000 with GOPS (dashed line, $n=3$ ). The vertical dotted line in $\mathbf{d}$ shows the PV value 50 ms after the light onset. e, f Representative traces from single electrodes of PV upon the delivery of a train stimulation composed of 20 pulses $(10 \mathrm{~ms}, 730 \mathrm{~nm}, 6 \mathrm{~mW} \mathrm{~mm}-2)$ delivered at $20 \mathrm{~Hz}$ with pristine PH1000 (f) and PH1000 with $1 \mathrm{v} / \mathrm{v} \%$ of GOPS (e).

stimulation (Fig. 4e), in contrast to the case when GOPS is not added (Fig. $4 \mathrm{f}$ ). This slower discharge rate is very likely caused by the reduction of the electrical conductivity due to the addition of $1 \mathrm{v} / \mathrm{v} \%$ of GOPS $\left(0.21 \mathrm{~S} \mathrm{~mm}^{-1}\right.$, average of 5 measures from 1 sample; film thickness of $170 \mathrm{~nm}$ ).

Hence, we investigated which concentration of GOPS could simultaneously increase the adhesion of the PEDOT:PSS film (PH1000) while preserving the photovoltaic performance. We fabricated a set of samples with five concentration of GOPS (0, $0.1,0.25,0.5$ and $1 \mathrm{v} / \mathrm{v} \%)$ and measured the PCD and PV. The mean PV $\left(730 \mathrm{~nm}, 6 \mathrm{~mW} \mathrm{~mm}^{-2}\right)$ increased immediately upon addition of GOPS, and it remained stable regardless of the concentration (Fig. 5a). Conversely, the mean PCD peak remains high up to $0.1 \mathrm{v} / \mathrm{v} \%$ of GOPS, and then it decreased. Therefore, one can designate a concentration of $0.1 \mathrm{v} / \mathrm{v} \%$ as the best compromise, since higher concentration would induce a strong reduction of the PCD generated by the photovoltaic pixels. In parallel, the increase in the concentration of GOPS increases the decay time at the offset of the light pulse (Fig. 5b). The fitting with a two-phase exponential decay function showed that both $\tau_{\text {fast }}$ and $\tau_{\text {slow }}$ increase with the GOPS concentration (Fig. 5c). However, with $0.1 \mathrm{v} / \mathrm{v} \%$ of GOPS, the electrode is fully discharged (i.e., the PV returns to baseline) in $40 \mathrm{~ms}$ from the pulse offset (Fig. 5d), allowing a stimulation pulse rate up to $20 \mathrm{~Hz}$. In summary, the chemical modification of PEDOT:PSS with 0.1 $\mathrm{v} / \mathrm{v} \%$ of GOPS allowed the optimization of the photovoltaic performance for an efficient stimulation. Both the resistance (Fig. 5e, white circles) and the thickness (Fig. 5f) of the PEDOT: PSS thin film are affected by the GOPS concentration. Accordingly, the film conductivity (computed by normalizing the average film resistance by the average film thickness) decreases with the increase of the GOPS concentration (Fig. 5e, black circles). This confirms that the conductivity of the PEDOT:PSS films plays a significant role in the optoelectronic properties of photovoltaic pixels.
To further investigate the role of GOPS in the adhesion of the PEDOT:PSS layer, we fabricated on polydimethylsiloxane (PDMS) photovoltaic retinal interfaces using the PCPDTBT: $\mathrm{PC}_{60} \mathrm{BM} \mathrm{BHJ}$ (nirPOLYRETINA). In this case, the photovoltaic retinal interface was not encapsulated to expose the organic layers to direct contact with water and allow faster delamination (Fig. 6a, b). Soaking experiments in saline solution revealed that the addition of $0.1 \mathrm{v} / \mathrm{v} \%$ of GOPS (Fig. 6c, middle) increases the adhesion of the photovoltaic pixels to the PDMS substrate compared to pristine PEDOT:PSS (Fig. 6c, left). On the other hand, a higher concentration of GOPS $(0.25 \mathrm{v} / \mathrm{v} \%$; Fig. $6 c$, right $)$ does not increase adhesion but induces delamination again. The addition of GOPS not only crosslinks the PSS molecules together, but it also anchors them to the substrate (e.g. PDMS). This explains the strengthened adhesion of PEDOT:PSS to PDMS. Nevertheless, a further increase in the GOPS concentration (e.g. from 0.1 to $0.25 \mathrm{v} / \mathrm{v} \%$ and above) induced delamination again, but at the interface between PEDOT:PSS and PCPDTBT:PC ${ }_{60} \mathrm{BM}$ rather than at the interface with PDMS.

We hypothesize that the increase of the cross-linking degree with GOPS could impair the diffusion of the PCPDTBT molecules into PEDOT:PSS during the thermal treatment after deposition. This lower interaction between the two polymeric layers would inevitably decrease the adhesion forces. To verify this hypothesis, we performed depth-profiling measurements with time-of-flight secondary ion mass spectrometry (ToF-SIMS) from the top surface of PCPDTBT:PC ${ }_{60} \mathrm{BM}$ to the bottom side of PEDOT:PSS (i.e., to the substrate) at various concentration of GOPS (Fig. 7a). The analysis of the negative polarity spectra indicates that with increasing GOPS concentration, $\mathrm{PC}_{60} \mathrm{BM}$ molecules (red curve, $\mathrm{C}_{60}-$ fragments) tend to accumulate at the interface towards PEDOT:PSS. Furthermore, the depth distribution of the $\mathrm{CN}^{-}$fragments (green curve) suggests a penetration of PCPDTBT molecules into the PEDOT:PSS layer when GOPS is not added. Based on the depth profiles of the relevant fragments, 

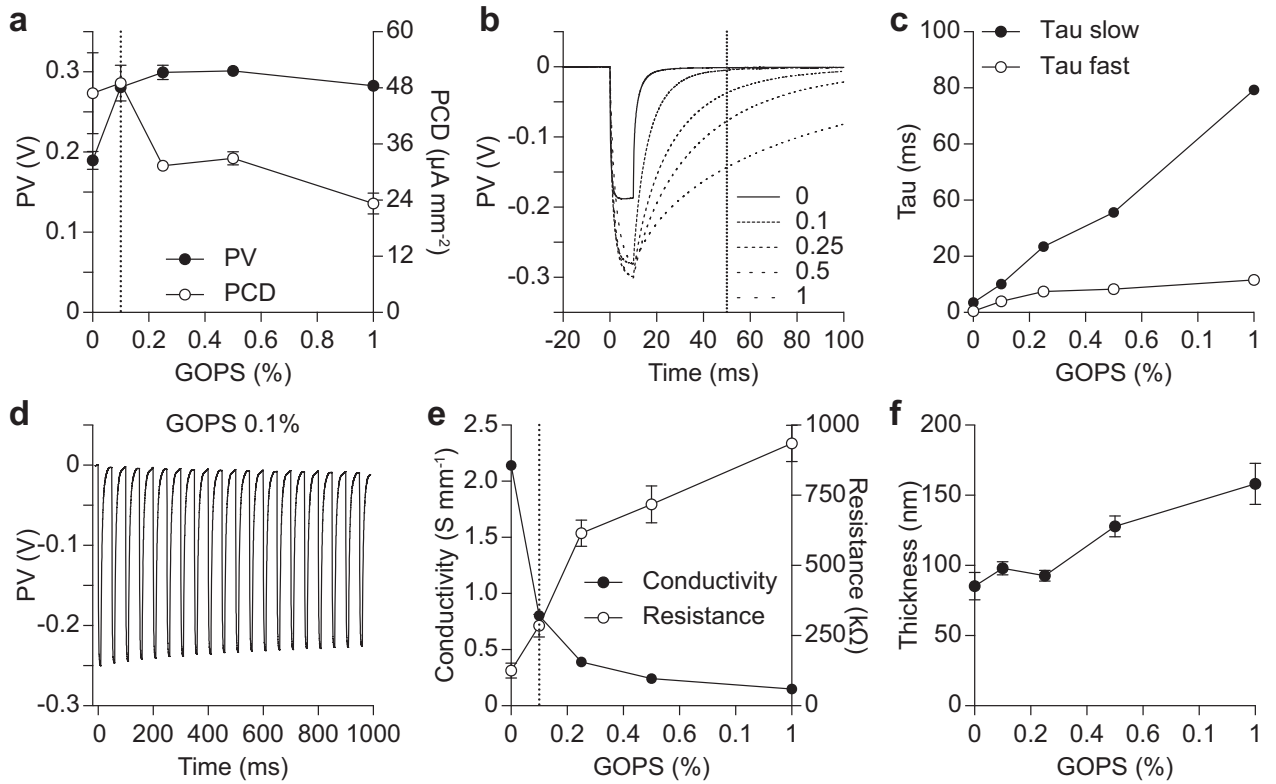

Fig. 5 Electrical tuning with the GOPS concentration. a Mean ( \pm s.e.m.) PCD (right axis) and PV (left axis) obtained upon 10-ms pulses (730 nm, $6 \mathrm{~mW} \mathrm{~mm}^{-2}$ ) with PH1000/PCPDTBT:PC ${ }_{60} \mathrm{BM} / \mathrm{Ti}$ supplemented with various concentrations of GOPS $(0,0.1,0.25,0.5,1 \mathrm{v} / \mathrm{v} \%, n=4 \mathrm{chips}$ for each concentration). The vertical dotted line highlights the values at $0.1 \mathrm{v} / \mathrm{v} \%$ of GOPS. b Grand-average ( $n=4$ chips for each concentration) PV traces obtained at the same conditions as in $\mathbf{a}$. The vertical dotted line shows the PV value $50 \mathrm{~ms}$ after the light onset. $\mathbf{c}$ Evolution of $\tau_{\text {fast }}$ and $\tau_{\text {slow }}$ as a function of the GOPS concentration. $\mathbf{d}$ Representative traces from a single electrode of PV upon 20 pulses $(10 \mathrm{~ms}, 730 \mathrm{~nm}, 6 \mathrm{~mW}$ mm-2) delivered at $20 \mathrm{~Hz}$ with PH1000 supplemented with $0.1 \mathrm{v} / \mathrm{v} \%$ of GOPS. e, Mean ( \pm s.d.; 12 measures from $n=2$ samples for each condition) resistance (white circles, right axis) and average conductivity (black circles, left axis) of PH1000 films with various concentrations of GOPS. The vertical dotted line highlights the values at $0.1 \mathrm{v} / \mathrm{v} \%$ of GOPS. $\mathbf{f}$ Mean ( \pm s.d.; 12 measures from $n=2$ samples for each condition) thickness of PEDOT:PSS (PH1000) films with various concentrations of GOPS.

a

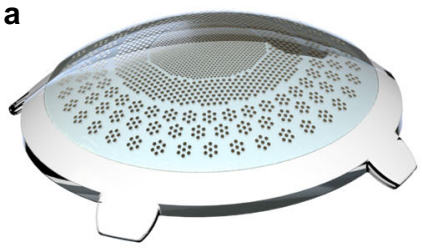

C

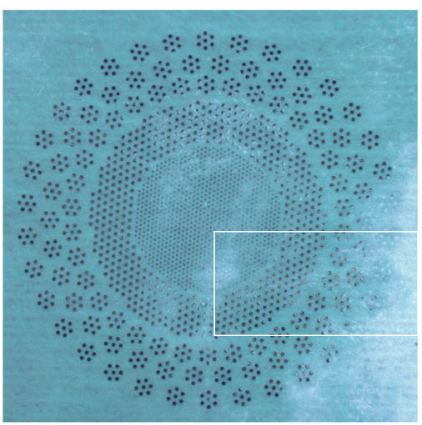

b

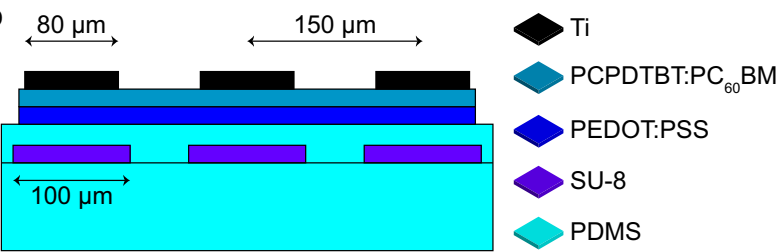

GOPS $0.1 \%$

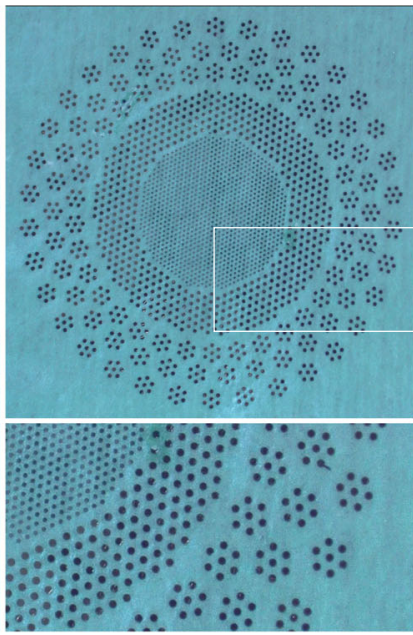

GOPS $0.25 \%$

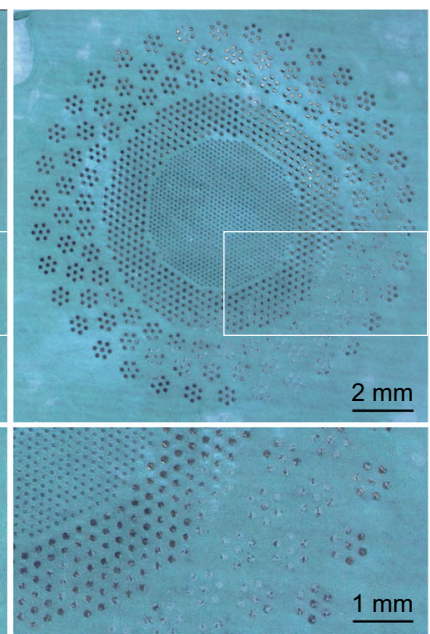

Fig. 6 Adhesion of the interface. a 3D model of the nirPOLYRETINA prosthesis. $\mathbf{b}$ Cross-section of the nirPOLYRETINA active interface, including: PDMS $(50 \mu \mathrm{m})$, a second layer of PDMS $(14 \mu \mathrm{m})$ embedding SU-8 rigid platforms $(6 \mu \mathrm{m})$, a layer of PEDOT:PSS with various percentages of GOPS, a layer of PCPDTBT:PC ${ }_{60} B M(100 \mathrm{~nm})$, and titanium cathodes $(150 \mathrm{~nm})$. c Pictures of nirPOLYRETINA devices prepared with $0,0.1$ and $0.25 \mathrm{v} / \mathrm{v} \%$ of $\mathrm{GOPS}$ after soaking in saline solution and ultra-sonication for $5 \mathrm{~min}$. 

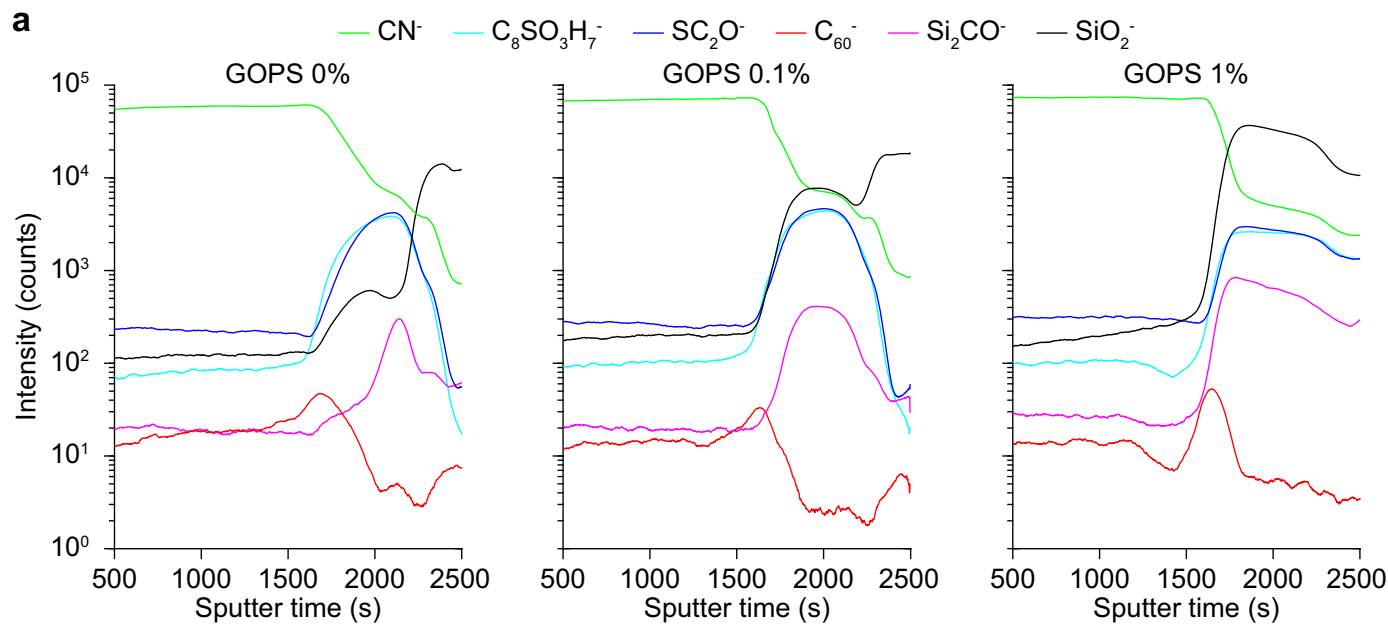

b

GOPS $0 \%$
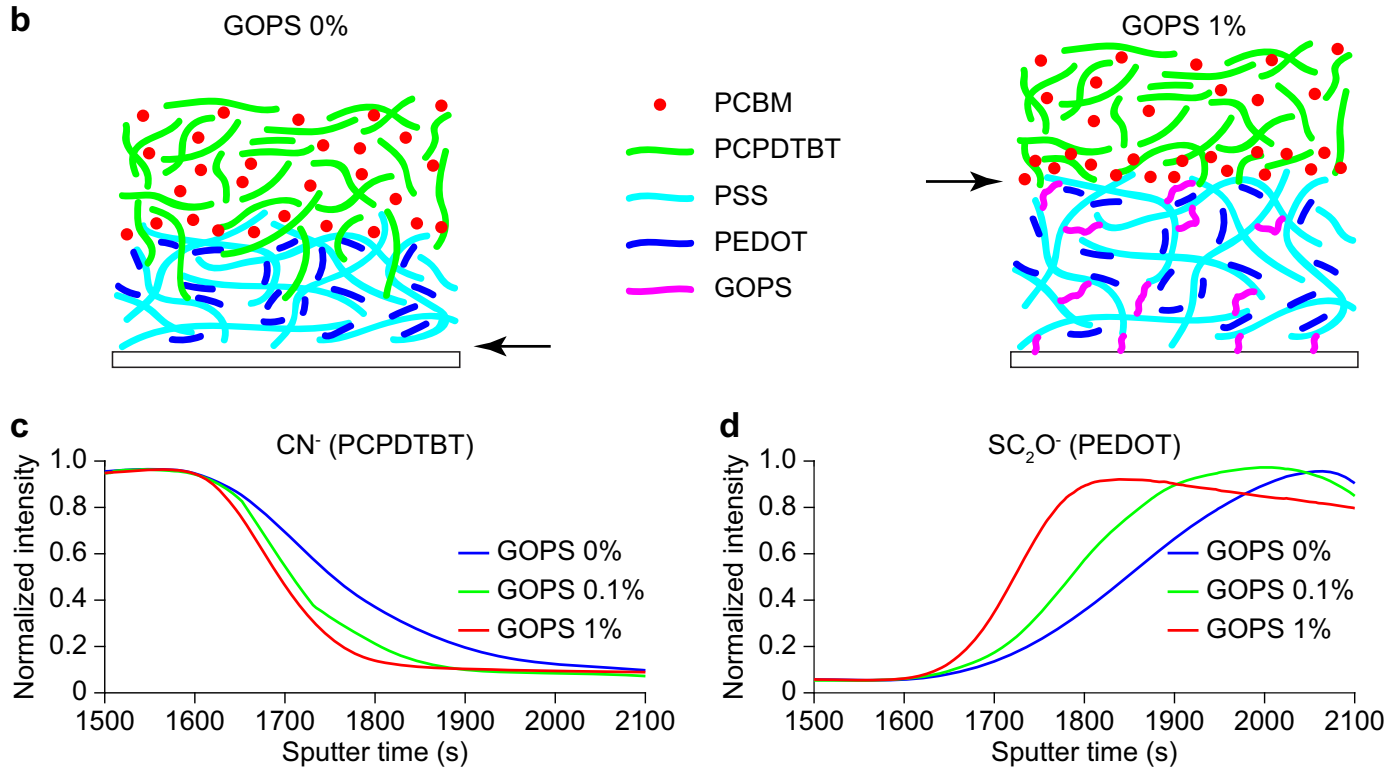

Fig. 7 Redistribution of molecules as a function of the GOPS concentration. a Smoothed ToF-SIMS depth profiles (negative polarity) conducted on the organic layers with $0,0.1$, and $1 \mathrm{v} / \mathrm{v} \%$ of GOPS. $\mathrm{CN}^{-}, \mathrm{C}_{8} \mathrm{SO}_{3} \mathrm{H}_{7}^{-}, \mathrm{SC}_{2} \mathrm{O}^{-}, \mathrm{C}_{60^{-}}, \mathrm{Si}_{2} \mathrm{CO}^{-}$, and $\mathrm{SiO}_{2}^{-}$are used as proxies respectively for PCPDTBT, PSS, PEDOT, $P C_{60} B M, G O P S$, and both glass and GOPS. The interface between PCPDTBT:PC ${ }_{60} B M$ and PEDOT:PSS is roughly at $1700 \mathrm{~s}$, while the one between PEDOT:PSS and the glass substrate is roughly at 2100,2250 and 2400 s for pristine PEDOT:PSS, with 0.1 v/v\% GOPS, and with 1 v/v\% GOPS, respectively. b Schematic representation of the deduced organization of the organic molecules for $0 \mathrm{v} / \mathrm{v} \%$ (left) and $1 \mathrm{v} / \mathrm{v} \%$ (right) of GOPS. The arrows indicate the observed delamination level within the organic layers. $\mathbf{c}, \mathbf{d}$ Normalized intensities of the depth profiles for PCPDTBT $\left(\mathrm{CN}^{-}\right)(\mathbf{c}) \mathrm{and} \mathrm{PEDOT}\left(\mathrm{SC}_{2} \mathrm{O}^{-}\right)(\mathbf{d})$ for the three GOPS concentrations.

we predicted the organization of the organic molecules and represented it for the two extreme GOPS concentrations: 0 and 1 $\mathrm{v} / \mathrm{v} \%$ (Fig. 7b). In Fig. 7c, the normalized intensities of the PCPDTBT signal ( $\mathrm{CN}^{-}$fragments) for the three different GOPS concentrations are plotted to efficiently compare their slopes, representing their distinct penetration depths into PEDOT:PSS. Moreover, the slope of the normalized intensities of the PEDOT signal $\left(\mathrm{SC}_{2} \mathrm{O}^{-}\right.$fragments) also shows a diffuse interface (slow rise) for $0 \mathrm{v} / \mathrm{v} \%$ and a sharper one (faster rise) for $1 \mathrm{v} / \mathrm{v} \%$ (Fig. 7d).

Therefore, we assume that PCPDTBT molecules are more easily able to penetrate the PEDOT:PSS network if the latter is less crosslinked, allowing an adhesive interface against delamination. Conversely, if PEDOT:PSS is supplemented with GOPS, $\mathrm{PC}_{60} \mathrm{BM}$ is placed at the interface with PEDOT:PSS, creating a brittle and more fragile interface where delamination can occur ${ }^{25}$. Hence, a concentration of $0.1 \mathrm{v} / \mathrm{v} \%$ of GOPS is optimal to enhance both the photovoltaic performance and the adhesion of the two interfaces.
Thermal management. The theoretical MPEs were computed based on safety standards ${ }^{21}$ without considering the presence of a photovoltaic implant in contact with the retina. When a photovoltaic retinal prosthesis (e.g. nirPOLYRETINA) is implanted, the incident light absorbed by the prosthesis generates additional heat that needs to be considered into the MPE. At $730 \mathrm{~nm}$, the theoretical MPE for continuous illumination is $2.4 \mathrm{~mW} \mathrm{~mm}^{-2}$. We used a Finite Element Method (FEM) to estimate the temperature increase in the retina upon photovoltaic illumination (Fig. 8). Without the photovoltaic retinal prosthesis, the temperature increase upon chronic illumination $(730 \mathrm{~nm}, 2.4 \mathrm{~mW}$ $\left.\mathrm{mm}^{-2}, 46.3^{\circ}, 150 \mathrm{~s}\right)$ at the interface between the retina and the retinal pigmented epithelium is stable at $0.78^{\circ} \mathrm{C}$ (Fig. 8a, d). This value might not exactly correspond to the real eye temperature increase due to the model approximations, such as the absorption and thermal coefficients of the eye structures, and will therefore only be used as a reference value. In this simulation, the POLYRETINA structure is present in the model, but all its domains 


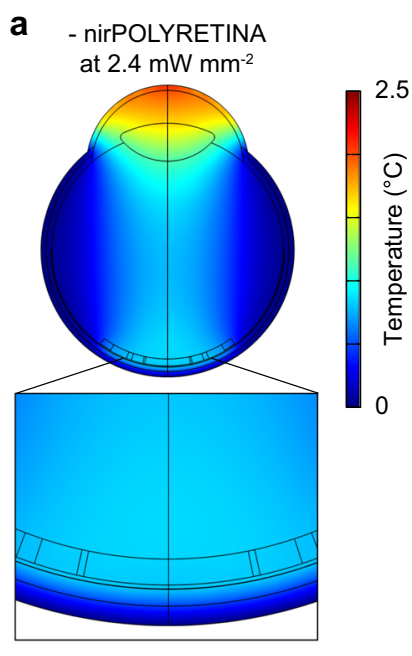

b + nirPOLYRETINA at $2.4 \mathrm{~mW} \mathrm{~mm}^{-2}$

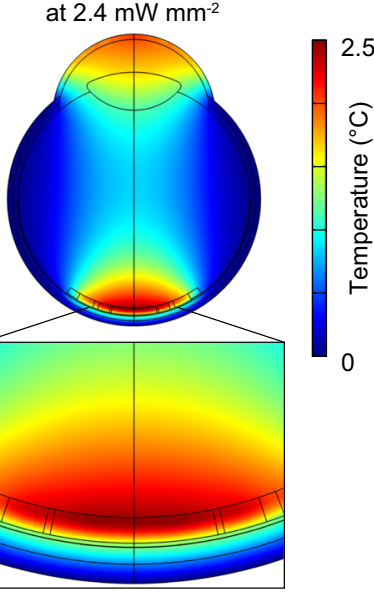

C + nirPOLYRETINA at $1.4 \mathrm{~mW} \mathrm{~mm}^{-2}$
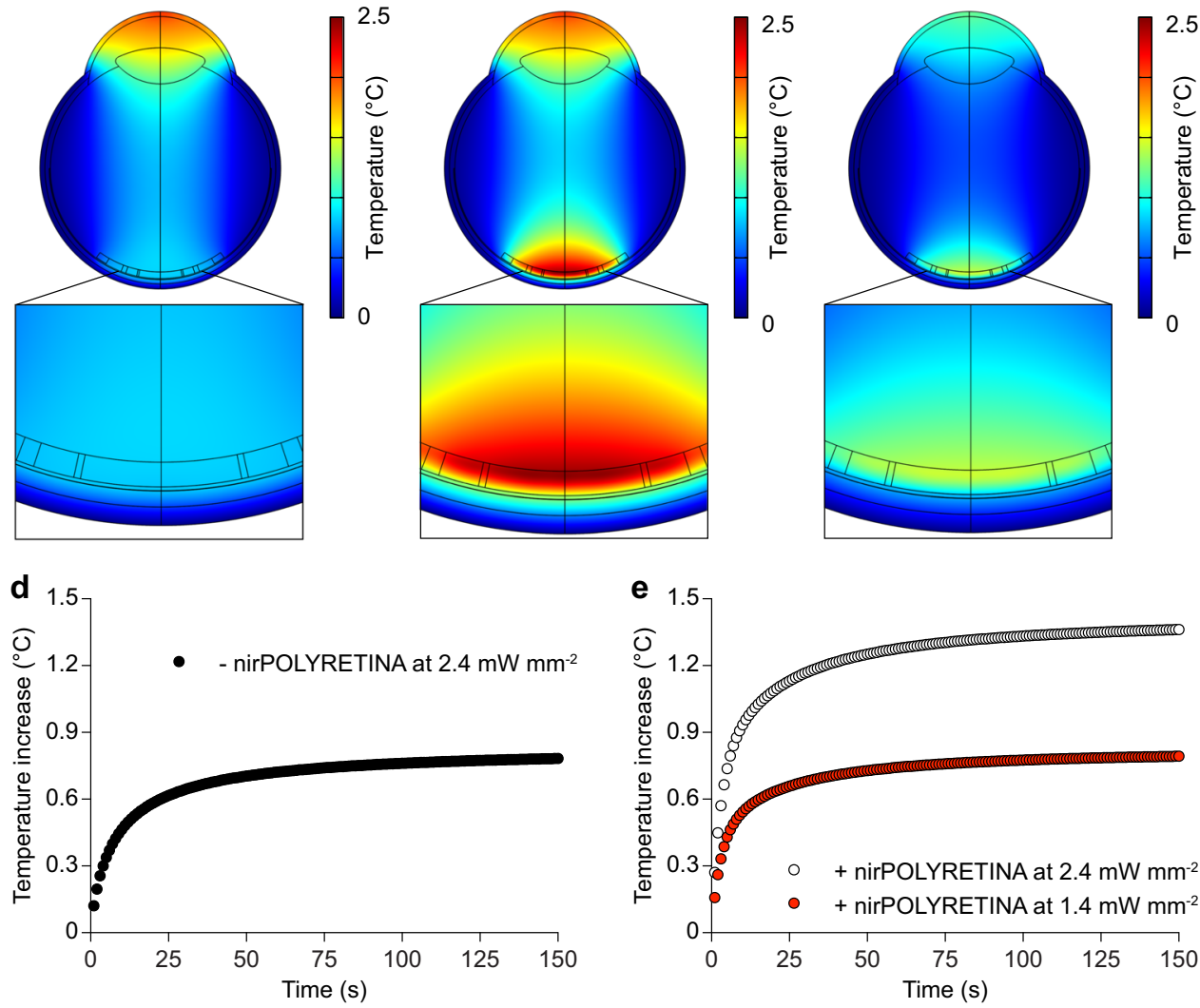

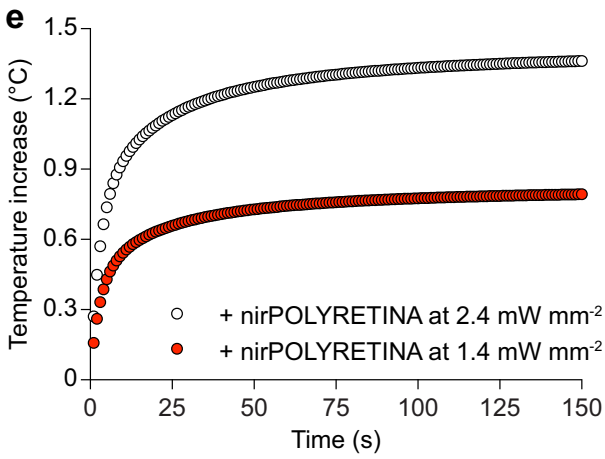

Fig. 8 Thermal simulations. a Temperature increase in the modelled eye after $150 \mathrm{~s}$ of continuous illumination $\left(730 \mathrm{~nm}, 2.4 \mathrm{~mW} \mathrm{~mm}^{-2}\right)$. The insert shows a larger view of the modelled retina. $\mathbf{b}, \mathbf{c}$ Temperature increase in the modelled eye with nirPOLYRETINA after $150 \mathrm{~s}$ of continuous illumination at $2.4 \mathrm{~mW} \mathrm{~mm}^{-2}(730 \mathrm{~nm}, \mathbf{b})$ and at $1.4 \mathrm{~mW} \mathrm{~mm}^{-2}(730 \mathrm{~nm}, \mathbf{c})$. The inserts show a larger view of the modelled retina and nirPOLYRETINA. d, e Time courses of the temperature increase in the modelled retina during $150 \mathrm{~s}$ of continuous illumination without nirPOLYRETINA at $2.4 \mathrm{~mW}$ mm ${ }^{-2}$ ( $730 \mathrm{~nm}$, black circles), with nirPOLYRETINA at $2.4 \mathrm{~mW} \mathrm{~mm}^{-2}$ (730 nm, white circles), and with nirPOLYRETINA at $1.4 \mathrm{~mW} \mathrm{~mm}^{-2}(730 \mathrm{~nm}$, red circles).

were set exactly as the vitreous humour. This solution allows a better comparison with the case when the nirPOLYRETINA is modelled in epi-retinal configuration (Fig. 8b, e). In the latter, the total temperature increase (at the retina-prosthesis interface) reaches a value of $1.36^{\circ} \mathrm{C}\left(730 \mathrm{~nm}, 2.4 \mathrm{~mW} \mathrm{~mm}^{-2}, 46.3^{\circ}, 150 \mathrm{~s}\right)$, which is 1.7 times higher than without the prosthesis. FEM simulations showed that the temperature increase with the photovoltaic retinal prosthesis is lowered back to $0.78^{\circ} \mathrm{C}$ (as without the implant) for a continuous irradiance of $1.4 \mathrm{~mW} \mathrm{~mm}^{-2}$, which is the adjusted MPE with nirPOLYRETINA for chronic photovoltaic stimulations at $730 \mathrm{~nm}$ (Fig. 8c, e). In the case of $10-\mathrm{ms}$ pulsed illumination, the adjusted MPEs are 7, 14 and $28 \mathrm{~mW} \mathrm{~mm}^{-2}$ respectively for an illumination rate of 20,10 and $5 \mathrm{~Hz}$.

Functional validation of the NIR-responsive photovoltaic prosthesis. PCPDTBT was used for bioelectronic interfaces only in few reports ${ }^{1,10}$. Therefore, we first investigated the in vitro cytotoxicity of the NIR-responsive photovoltaic prosthesis fabricated on a PDMS substrate (Fig. 9a). A mean cell viability ( \pm s.e.m.; $n=4$ samples) of $107.725 \pm 0.520$ was obtained (negative control $100 \%, n=1$ sample; positive control $0 \%, n=1$ sample), thus confirming the non-toxicity of the prosthesis in passive condition (i.e. without pulsed illumination). For each sample the test was performed on triplicate cultures wells and data were averaged (Fig. 9b). A one-way ANOVA analysis $(p<0.0001, F=223.9)$ revealed that all the four prostheses tested resulted in a cell viability significantly higher than the positive control $(p<0.0001$ for all, Tukey multiple comparisons); similarly, the negative control is significantly higher than the positive control $(p<0.0001$, Tukey multiple comparisons). There was no statistically significant difference among the four prostheses and against the negative control ( 1 vs $2: p=0.9947 ; 1$ vs $3: p>0.9999 ; 1$ vs $4: p>0.9999 ; 2$ vs 3 : $p=9989 ; 2$ vs $4: p=0.9920 ; 3$ vs $4: p>0.9999 ; 1$ vs negative control: $p=0.5401 ; 2$ vs negative control: $p=0.2888 ; 3$ vs negative control: $p=0.4598 ; 4$ vs negative control: $p=0.5678$; Tukey multiple comparisons).

We also verified that the NIR-responsive photovoltaic prosthesis was able to stimulate retinal cells ex vivo. Explanted retinas from 4-months-old retinal degeneration 10 mice, an established model for retinitis pigmentosa ${ }^{26-28}$, were placed onto a microelectrode array and the responses evoked by photovoltaic stimulation (10-ms light pulses, $4.7 \mathrm{~mW} \mathrm{~mm}^{-2}$ ) were recorded from retinal ganglion cells (Fig. 9c). At this age, such retinas do not anymore exhibit light responsivity ${ }^{29}$. NIR light pulses were able to significantly induce firing activity in retinal ganglion cells (Fig. 9d) at a safe irradiance level, compared to equivalent recordings without light pulses (Fig. 9e). We measured the average post-stimulus firing rate in a $300-\mathrm{ms}$ window after the light onset, or in the equivalent window when light pulses were not delivered. This large window compensates for the cell to cell variability in the onset of the spiking response and accounts for both transient and sustained responses, even if the response of transient retinal ganglion cells might result underestimated. NIR light pulses induced a significantly higher response compered to recordings without light pulses (Fig. 9f; $p=0.034$, two-tailed paired $t$-test). This result showed that the NIR-responsive 
a

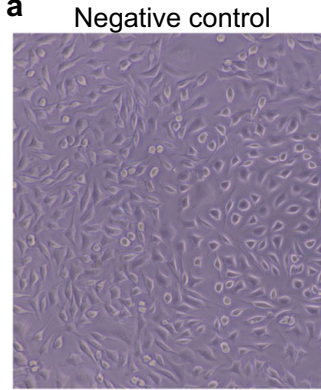

C

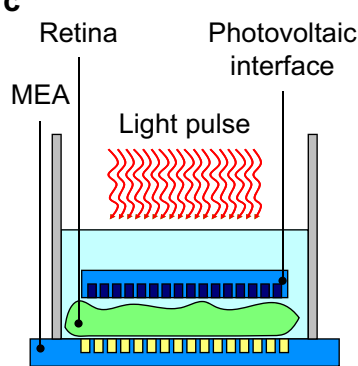

Positive control
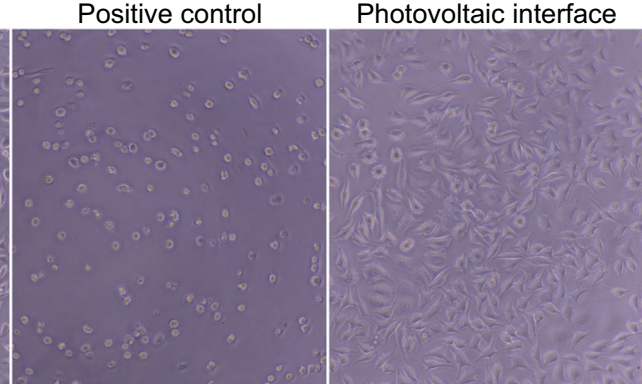

d Light

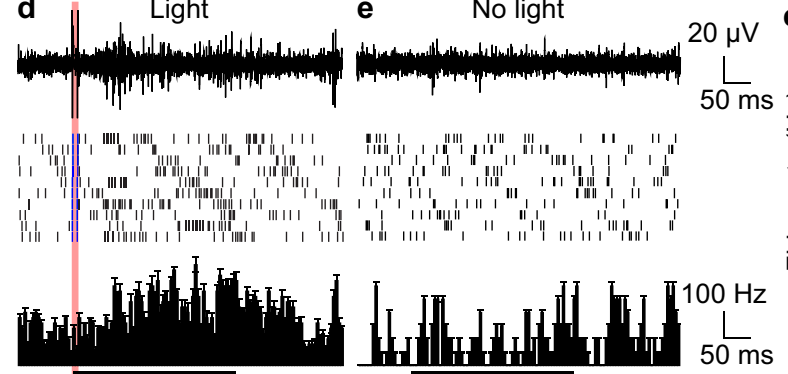

b

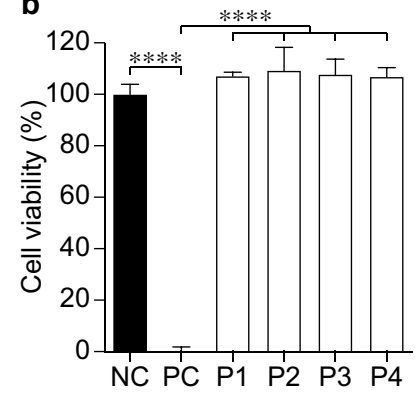

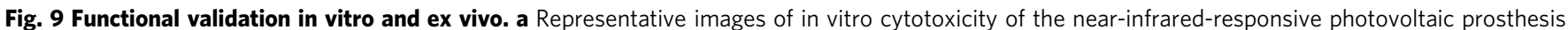

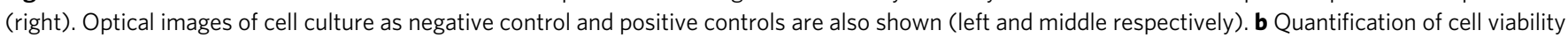
of the four prostheses tested (from P1 to P4) along with the negative and positive controls (respectively NC and PC). c Sketch of the setup used for ex vivo electrophysiology. d Representative response of one retinal ganglion cell upon NIR stimulation (10 ms, $4.7 \mathrm{~mW}$ mm-2; identified by the red bar). The top row shows the electrophysiological recordings upon one NIR light pulse. The middle row shows the raster plots upon ten consecutive NIR light pulses. The blue lines in the raster correspond to the events classified as stimulus artefacts. The bottom row shows the corresponding mean post-stimulus time histogram ( \pm s.d., bins of $5 \mathrm{~ms}$ ). The 300 -ms black bar corresponds to the time window averaged to determine the post-stimulus mean firing rate.

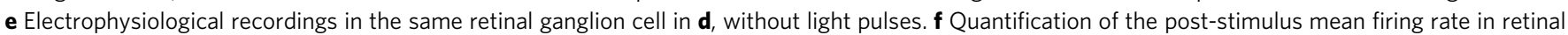
ganglion cells with $(\mathrm{L})$ and without $(\mathrm{NL})$ NIR light pulses $(n=21$ retinal ganglion cells; two-tailed paired $t$-test, $\mathrm{p}=0.034)$. Bars are means $\pm \mathrm{s}$.d.

photovoltaic prosthesis can effectively be used for retinal stimulation. The irradiance level used $\left(4.7 \mathrm{~mW} \mathrm{~mm}^{-2}\right)$ corresponds to $67 \%$ of the adjusted MPEs at $20 \mathrm{~Hz}$ illumination rate, $33.5 \%$ at $10 \mathrm{~Hz}$, and $16.75 \%$ at $5 \mathrm{~Hz}$. It remains to determine what will be the optimal illumination rate for photovoltaic retinal prostheses, like POLYRETINA. Clinical results tend to suggest that an increase of the pulse rate above $10 \mathrm{~Hz}$ might not necessarily be the most benefiting strategy to elicit relevant perception in implanted patients. A personalized trade-off between high stimulation rates allowing flicker fusion (e.g. $40 \mathrm{~Hz}$ in Argus II patients) but affecting the percept strength and duration and lower stimulation rates resulting in sustained but blinking percepts should be determined ${ }^{30}$. Patients implanted with either subretinal ${ }^{31,32}$ or epiretinal ${ }^{33-35}$ prostheses tend to prefer low stimulus frequencies. Recent ex vivo evidence also identifies stimulation frequencies from 5 to $10 \mathrm{~Hz}$ as the preferred frequency range to activate bipolar cells from the epiretinal side and trigger network-mediated responses in retinal ganglion cells ${ }^{36,37}$.

\section{Discussion}

Photovoltaics is an attractive approach in bioelectronic medicine and neuroprosthetics to stimulate or modulate neuronal activity. Our results show that organic photovoltaic interfaces can be optimized to achieve higher stability, better optoelectronic performances, and adjusted sensitivity in order to match the desired target application. In a proof-of-concept, we demonstrated the advantage of a NIR-responsive neuroprosthesis for retinal stimulation that allows for higher compliance with the standards for optical safety and reduces the interfering with the residual natural vision.
The use of NIR light for artificial vision was first introduced with silicon-based photovoltaic retinal prostheses ${ }^{38-40}$, which were considered better suited for photovoltaic stimulation because of the higher NIR photoconversion efficiency of silicon compared to conjugated polymers. In organic technology, previous researches attempted to perform retinal stimulation at longer wavelengths, even if still in the visible spectrum $^{41}$, and a computational study showed that a photovoltaic interface based on conjugated polymers could operate in the NIR spectrum ${ }^{42}$; however, in the latter study, an experimental validation was not provided. We demonstrated that also organic photovoltaic interfaces can efficiently stimulate blind retinas at NIR wavelengths (i.e. $730 \mathrm{~nm}$ ). This represents an important contribution to the development of organic retinal implants. Organic photovoltaic bioelectronic interfaces are facing additional challenges, such as optimizing the electrical properties of the photovoltaic cell to meet the required working conditions and the weak stability of the organic materials due to water-induced swelling, degradation, and delamination. Our study addressed these open challenges to advance the exploitation of conjugated polymers in photovoltaic organic prostheses.

\section{Methods}

Chip micro-fabrication. Samples were fabricated on $20 \times 24 \mathrm{~mm}^{2}$ glass substrates (2947-75X50, Corning Incorporated) cleaned by ultra-sonication in acetone, isopropyl alcohol, and deionized water for $15 \mathrm{~min}$ each and then dried with a nitrogen gun. The deposition of the PEDOT:PSS and the preparation of the bulk heterojunctions were performed in a glovebox under nitrogen atmosphere. PEDOT:PSS (HTL Solar and PH1000, Clevios) was filtered (1- $\mu \mathrm{m}$ PTFE filters) then spin-coated at $3000 \mathrm{rpm}$ for $40 \mathrm{~s}$ on each sample. Subsequent annealing at $115^{\circ} \mathrm{C}$ for $30 \mathrm{~min}$ was performed. When present, GOPS was added to the solution before filtering. $20 \mathrm{mg}$ of P3HT (698997, Sigma Aldrich) or PCPDTBT (754005-100MG, Sigma) and $20 \mathrm{mg}$ of $\mathrm{PC}_{60} \mathrm{BM}$ (M111, Ossila) were dissolved in $1 \mathrm{~mL}$ of anhydrous 
chlorobenzene each and let stirring overnight at $70^{\circ} \mathrm{C}$. The solutions were then filtered $\left(0.45 \mu \mathrm{m}\right.$ PTFE filters) and blended [1:1 v-v]. The P3HT:PC ${ }_{60} \mathrm{BM}$ (nominal thickness $100 \mathrm{~nm}$ ) and PCPDTBT:PC ${ }_{60} \mathrm{BM}$ (nominal thickness $100 \mathrm{~nm}$ ) blends were then spin-coated at $1000 \mathrm{rpm}$ for $45 \mathrm{~s}$. Subsequent annealing at $115^{\circ} \mathrm{C}$ for 30 min was performed. Titanium cathodes (diameter $100 \mu \mathrm{m}$, nominal thickness $150 \mathrm{~nm}$ ) were deposited by DC magnetron sputtering through a shadow mask. A plastic reservoir was then attached to the sample using PDMS as adhesive.

Measure of photo-voltage and photo-current. Samples were placed on a holder, and each electrode was sequentially contacted. A platinum wire immersed in physiological saline solution ( $\mathrm{NaCl} 0.9 \%)$ was used as counter electrode. In all, 10 -ms light pulses were delivered by a $565-\mathrm{nm}$ (M565L3, Thorlabs), 730-nm (M730L4, Thorlabs), or 780-nm (M780LP1, Thorlabs) LED focused at the sample level. Photo-voltage and photo-current were measured using respectively a voltage amplifier (1201, band DC-3000 Hz, DL-Instruments) and a current amplifier (1212, DL-Instruments). Data sampling $(40 \mathrm{kHz})$ and instrument synchronization were obtained via a DAQ board (PCIe-6321, National Instruments) and custommade software. Data analysis was performed in MATLAB (MathWorks). When evaluating the photo-current density generated by the interface, also the area of the connecting line exposed to light has been considered.

Spectral absorbance. The preparation of the bulk heterojunctions was performed as before. The thicknesses were 80 and $62 \mathrm{~nm}$ for P3HT:PC ${ }_{60} \mathrm{BM}$ and PCPDTBT: $\mathrm{PC}_{60} \mathrm{BM}$ respectively. The absorbance spectra of the thin films were measured using a UV-vis-NIR UV-3600 Shimadzu spectrophotometer.

Resistance measurements. The preparation of the PEDOT:PSS was performed as before. The film resistance was measured with a custom 4-point prober $(2.5 \mathrm{~mm}$ pitch distance) using a Keithley 2400 source-meter. Each sample was measured on five different locations randomly distributed on the surface.

Thickness measurements. Thin-film thickness was measured in PeakForce tapping mode (ScanAsyst Air silicon tip, $f_{0}=70 \mathrm{kHz}, k=0.4 \mathrm{~N} \mathrm{~m}^{-1}$ ) with a Dimension Icon AFM (Bruker).

Time-of-flight secondary ion mass spectrometry measurements. The measurements were performed on a ToF-SIMS.5 instrument (IONTOF, Germany) operated in the spectral mode using a $25 \mathrm{keV} \mathrm{Bi}^{3+}$ primary ion beam with an ion current of $0.81 \mathrm{pA}$. A mass resolving power in the range of $5000 \mathrm{~m} \mathrm{sm}^{-1}$ was reached. For depth profiling, a $500 \mathrm{eV} \mathrm{Cs}^{+}$sputter beam with a current of $43.47 \mathrm{nA}$ was used. The raster area of the sputter beam was $500 \mu \mathrm{m} \times 500 \mu \mathrm{m}$, and the mass spectrometry was performed on an area of $200 \mu \mathrm{m} \times 200 \mu \mathrm{m}$ in the center of the sputter crater. A low-energy electron flood gun was used for charge compensation.

Fabrication of nirPOLYRETINA prostheses. Prostheses were prepared as previously described ${ }^{14}$. A thin sacrificial layer of poly(4-styrenesulfonic acid) solution (561223, Sigma-Aldrich) was spin-coated on $4^{\prime \prime} \mathrm{Si}$ wafers (1000 rpm, $40 \mathrm{~s}$ ) and baked $\left(120^{\circ} \mathrm{C}, 15 \mathrm{~min}\right)$. Degassed PDMS pre-polymer (10:1 ratio base-to-curing agent, Sylgard 184, Dow-Corning) was then spin-coated (1000 rpm, $60 \mathrm{~s}$ ) and cured in oven $\left(80^{\circ} \mathrm{C}, 2 \mathrm{~h}\right)$. After surface treatment with oxygen plasma $(30 \mathrm{~W}, 30 \mathrm{~s})$, a $6 \mu \mathrm{m}$ thick SU-8 (GM1060, Gersteltec) layer was spin-coated $(3800 \mathrm{rpm}, 45 \mathrm{~s})$, softbaked $\left(110^{\circ} \mathrm{C}, 300 \mathrm{~s}\right)$, exposed $\left(140 \mathrm{~mJ} \mathrm{~cm}^{-2}, 365 \mathrm{~nm}\right)$, post-baked $\left(90^{\circ} \mathrm{C}, 1800 \mathrm{~s}\right.$; $\left.60^{\circ} \mathrm{C}, 2700 \mathrm{~s}\right)$, developed in propylene glycol monomethyl ether acetate (48443, Sigma-Aldrich) for $2 \mathrm{~min}$, rinsed in isopropyl alcohol, and dried with nitrogen gun. After surface treatment with oxygen plasma $(30 \mathrm{~W}, 30 \mathrm{~s})$, a second layer of degassed PDMS pre-polymer (10:1) was spin-coated (3700 rpm, $60 \mathrm{~s})$ and cured in oven $\left(80^{\circ} \mathrm{C}, 2 \mathrm{~h}\right.$ ). The PEDOT:PSS (PH1000) film, the PCPDTBT:PC ${ }_{60} \mathrm{BM}$ film, and the titanium cathodes were prepared as described above. The photovoltaic membrane was then released from the wafer and plasma bonded to a PDMS domeshaped support with a $12 \mathrm{~mm}$ curvature radius an average thickness of $600 \mu \mathrm{m}$.

Soaking experiments. nirPOLYRETINA devices were soaked in saline solution $(\mathrm{NaCl} 0.9 \%)$ at $37^{\circ} \mathrm{C}$ and ultra-sonication was applied for $5 \mathrm{~min}$.

Cytotoxicity test. The test was conducted according to ISO 10993-5: Biological Evaluation of Medical Devices, in vitro cytotoxicity test. Prostheses were sterilized in a dry oven for $2 \mathrm{~h}$ at $120^{\circ} \mathrm{C}$. The test on extraction was performed with samples for a total surface area of $3.54 \mathrm{~cm}^{2}$ each, with a ratio of the product to extraction vehicle of $3 \mathrm{~cm}^{2} \mathrm{ml}^{-1}$. Extraction vehicle was Eagle's Minimum Essential Medium supplemented with fetal bovine serum, penicillin-streptomycin, amphotericin B, and L-glutamine. The extraction was performed for $24 \mathrm{~h}$ at $37^{\circ} \mathrm{C}$. For each sample, the extract was added on triplicate cultures wells containing a sub-confluent L929 cell monolayer. The test samples and the control wells were incubated at $37^{\circ} \mathrm{C}$ in $5 \% \mathrm{CO}_{2}$ for $24 \mathrm{~h}$. Following incubation, the cell cultures were examined for quantitative cytotoxic evaluation. In all, $50 \mu \mathrm{l}$ per well of XTT reagent were added to the cells then incubated at $37^{\circ} \mathrm{C}$ in $5 \% \mathrm{CO}_{2}$ for further $3-5 \mathrm{~h}$. An aliquot of
$100 \mu \mathrm{l}$ was then transferred from each well into the corresponding wells of a new plate and the optical density was measured at $450 \mathrm{~nm}$.

Electrophysiology ex vivo. Animal experiments were performed according to the animal authorizations GE3717 approved by the Département de l'Emploi, des Affaires sociales et de la Santé (DEAS), Direction Générale de la Santé of the République et Canton de Genève (Switzerland). Male and female mice from a homozygous colony of retinal degeneration 10 mice (B6.CXB1-Pde6 $\mathrm{b}^{\mathrm{rd} 10} / \mathrm{J}$, The Jackson Laboratory, Stock number: 004297) were used for the experiments. All animals were kept in a $12 \mathrm{~h}$ day/night cycle with access to food and water ad libitum. All the experiments were carried out during the day cycle. Eyes were enucleated from euthanized mice (sodium pentobarbital, $150 \mathrm{mg} \mathrm{kg}^{-1}$ ) and dissected in carboxygenated $\left(95 \% \mathrm{O}_{2}\right.$ and $5 \% \mathrm{CO}_{2}$ ) Ames' medium (A1420, SigmaAldrich) under dim red light. Retinas were placed ganglion cells down and maintained in contact with a transparent microelectrode array with 256 electrodes (256MEA200/30iR-ITO, Multi Channel Systems). The NIR-responsive, polymeric and photovoltaic neuroprosthesis was placed on top of the retina, and both the retina and the prosthesis were kept in position using a $1 \mathrm{~mm}$ nylon mesh. Retinas were continuously superfused with carboxygenated Ames' medium at $32{ }^{\circ} \mathrm{C}$ and maintained under dim red light during all the experiments. Light stimuli were generated using a 730-nm light emitting diode (M730L4, Thorlabs) paired to a $\times 20$ objective (CFI Plan Apochromat Lambda, Nikon Instruments). The diameter of the light spot was $4.16 \mathrm{~mm}$. The signal from the 256 recording electrodes was amplified, filtered $(300-3000 \mathrm{~Hz}$ ), and digitalized at $10 \mathrm{kHz}$ (USB-MEA256-System, Multi Channel Systems). Spike detection was performed with the MC_rack software (Multi Channel Systems), and the results were further processed with Neuroexplorer (Neuronexus) and MATLAB. For each cell, the post-stimulus mean firing rate was measured from the PSTH within a 300 -ms time window after the light onset.

Optical safety. Retinal damage upon light exposure can occur because of three main factors: photo-thermal damage, photo-chemical damage, and thermoacoustic damage ${ }^{21,43}$. For 10 -ms light pulses delivered at $20 \mathrm{~Hz}$, the MPE could be controlled by the photo-thermal $\left(\mathrm{MPE}_{\mathrm{T}}\right)$ or photo-chemical damage $\left(\mathrm{MPE}_{\mathrm{C}}\right)$, according to Eqs. (1) and (2), respectively.

$$
\begin{aligned}
\mathrm{MPE}_{\mathrm{T}} & =6.93 \cdot 10^{-5} C_{E} C_{T} \frac{1}{P} \\
\mathrm{MPE}_{\mathrm{C}} & =5.56 \cdot 10^{-10} C_{B} \alpha^{2}
\end{aligned}
$$

For the POLYRETINA prosthesis, the visual angle of is $\alpha=808.12 \mathrm{mrad}$ with an exposed area of $144.22 \mathrm{~mm}^{214}$. For $\lambda=565 \mathrm{~nm}$, both limits apply and $C_{E}=6.67$. $10^{-3} \alpha^{2} ; C_{T}=1 ; P=5.44 ; C_{B}=10^{0.02(\lambda-450)}$. The limits are $\mathrm{MPE}_{\mathrm{T}}=55.49 \mathrm{~mW}$ and $\mathrm{MPE}_{\mathrm{C}}=72.45 \mathrm{~mW}$. Therefore, the limiting factor is $\mathrm{MPE}_{\mathrm{T}}$ which results in $55.49 \mathrm{~mW}$ and corresponds to $384.75 \mu \mathrm{W} \mathrm{mm}$ m $^{-2}$ for an exposed area of $144.22 \mathrm{~mm}^{2}$. For $\lambda=730 \mathrm{~nm}$ and $780 \mathrm{~nm}$, only the $\mathrm{MPE}_{\mathrm{T}}$ applies and $C_{E}=$ $6.67 \cdot 10^{-3} \alpha^{2} ; C_{T}=10^{0.002(\lambda-700)} ; P=1 ; C_{B}=1000$. Therefore, for $\lambda=730 \mathrm{~nm}$ the $\mathrm{MPE}_{\mathrm{T}}$ is $346.59 \mathrm{~mW}$, which corresponds to $2.40 \mathrm{~mW} \mathrm{~mm}^{-2}$ for an exposed area of $144.22 \mathrm{~mm}^{2}$. For $\lambda=780 \mathrm{~nm}$, the $\mathrm{MPE}_{\mathrm{T}}$ is $436.33 \mathrm{~mW}$, which corresponds to $3.03 \mathrm{~mW} \mathrm{~mm}^{-2}$ for an exposed area of $144.22 \mathrm{~mm}^{2}$.

Thermal model. COMSOL Multiphysics 5.3 was used with the Bioheat module and the General PDE module for the heat transfer and Beer-Lambert light propagation. A uniform beam with a diameter of $13 \mathrm{~mm}$ was used as illumination source. The eye model was built with several spheres representing each component (cornea, aqueous humor, lens, vitreous humor, retina, retinal pigmented epithelium, choroid, and sclera). All the parameters used in the model are listed in Table 1.

The nirPOLYRETINA was divided into six domains with homogeneous properties. For each domain, the heat capacity, the thermal conductivity (thermal resistance circuit), the density, and the absorption coefficient (BeerLambert law; for titanium, a reflectance of 0.63 was considered ${ }^{57}$ ) were computed (Table 2). In case of domains D1, D3 and D5, the thermal conductivity and absorption coefficient were computed independently for the area with titanium/SU8 and for the area without. The two values were weighted proportionally to their respective area to obtain the final aggregated values listed in Table 2. For the density and the heat capacity, the aggregated values were directly weighted proportionally to the volume of each materials composing the domain. Domains D2 and D4 do not contain titanium nor SU8. Domain D6 is composed by PDMS only.

Statistical analysis and graphical representation. Statistical analysis and graphical representation were performed with Prism (GraphPad Software Inc.). The normality test (D’Agostino \& Pearson omnibus normality test) was performed in each dataset to justify the use of a parametric or non-parametric test. In each figure $p$-values were represented as: ${ }^{*} p<0.05,{ }^{* *} p<0.01,{ }^{* * *} p<0.001$ and ${ }^{* * * *} p<0.0001$ 
Table 1 Eye parameters for the FEM model.

\begin{tabular}{|c|c|c|c|c|c|c|c|}
\hline Material & $\begin{array}{l}\text { Thickness } \\
\mu \mathrm{m}\end{array}$ & 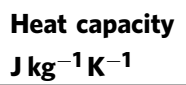 & $\begin{array}{l}\text { Thermal conductivity } \\
\mathbf{W ~ m}^{-1} K^{-1}\end{array}$ & $\begin{array}{l}\text { Density } \\
\mathrm{Kg} \mathrm{m}^{-3}\end{array}$ & $\begin{array}{l}\text { Absorption }(700-750 \mathrm{~nm}) \\
\mathrm{m}^{-1}\end{array}$ & $\begin{array}{l}\text { Perfusion rate } \\
s^{-1}\end{array}$ & $\begin{array}{l}\text { Self-heat } \\
\mathbf{W} \mathbf{m}^{-3}\end{array}$ \\
\hline Aqueous humor & 3100 & 3997 & 0.58 & 1000 & 17 & 0 & 0 \\
\hline Choroid & 430 & 3840 & 0.53 & 1050 & 600 & 0.0091 & 10000 \\
\hline Cornea & 500 & 4178 & 0.58 & 1050 & 125 & 0 & 0 \\
\hline Lens & 3600 & 3000 & 0.4 & 1050 & 17 & 0 & 0 \\
\hline Retina & 100 & 3680 & 0.565 & 1000 & 125 & 0 & 0 \\
\hline RPE & 10 & 4178 & 0.603 & 1050 & 20000 & 0 & 0 \\
\hline Sclera & 500 & 4178 & 0.58 & 1000 & 180 & 0 & 0 \\
\hline Vitreous humour & / & 3997 & 0.6 & 1000 & 17 & 0 & 0 \\
\hline PDMS & 670 & 1100 & 0.18 & 970 & 217 & 0 & 0 \\
\hline SU-8 & 6 & 1200 & 0.3 & 1200 & 4367 & 0 & 0 \\
\hline PEDOT:PSS & 0.1 & 2370 & 0.29 & 1011 & 539579 & 0 & 0 \\
\hline PCPDTBT:PCBM & 0.09 & 2800 & 0.15 & 1100 & 2979723 & 0 & 0 \\
\hline Titanium & 0.08 & 522 & 5 & 4430 & 19809072 & 0 & 0 \\
\hline
\end{tabular}

Table 2 Aggregated parameters for nirPOLYRETINA.

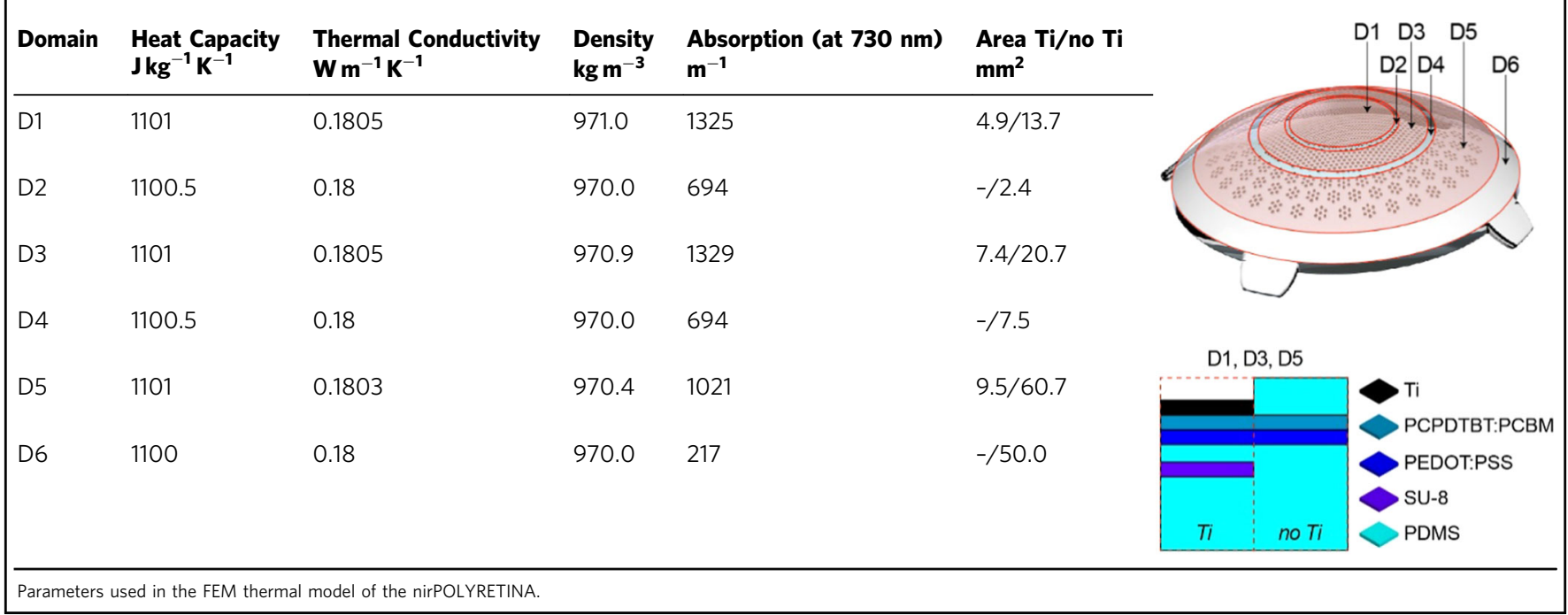

Reporting summary. Further information on research design is available in the Nature Research Reporting Summary linked to this article.

\section{Data availability}

All data are present in the paper. Original data related to this paper may be requested from the corresponding author upon reasonable request. Raw data related to ex vivo electrophysiology is accessible at https://doi.org/10.6084/m9.figshare.12018663.

Received: 12 November 2019; Accepted: 27 March 2020;

Published online: 01 May 2020

\section{References}

1. Feyen, P. et al. Light-evoked hyperpolarization and silencing of neurons by conjugated polymers. Sci. Rep. 6, 22718 (2016)

2. Lanzani, G., Antognazza, M., Martino, N., Ghezzi, D. \& Benfenati, F. Controlling Cell Functions by Light. in Proc. 2015 7th International IEEE/ EMBS Conference on Neural Engineering (NER) 603-606 (IEEE, 2015). https:// doi.org/10.1109/ner.2015.7146695.

3. Martino, N. et al. Photothermal cellular stimulation in functional bio-polymer interfaces. Sci. Rep. 5, 8911 (2015).

4. Antognazza, M. et al. Shedding light on living cells. Adv. Mater. 27, 7662-7669 (2015).
5. Ghezzi, D. et al. A polymer optoelectronic interface restores light sensitivity in blind rat retinas. Nat. Photonics 7, 400-406 (2013).

6. Martino, N., Ghezzi, D., Benfenati, F., Lanzani, G. \& Antognazza, M. Organic semiconductors for artificial vision. J. Mater. Chem. B 1, 3768-3780 (2013).

7. Ghezzi, D. et al. A hybrid bioorganic interface for neuronal photoactivation. Nat. Commun. 2, 166 (2011).

8. Lodola, F., Martino, N., Tullii, G., Lanzani, G. \& Antognazza, M. Conjugated polymers mediate effective activation of the Mammalian Ion Channel Transient Receptor Potential Vanilloid 1. Sci. Rep. 7, 8477 (2017).

9. Tortiglione, C. et al. Semiconducting polymers are light nanotransducers in eyeless animals. Sci. Adv. 3, e1601699 (2017).

10. Vaquero, S. et al. Conjugated polymers for the optical control of the electrical activity of living cells. J. Mater. Chem. B 4, 5272-5283 (2016).

11. Gribi, S., Dunilac, S., du, B., de, Ghezzi, D. \& Lacour, S. P. A microfabricated nerve-on-a-chip platform for rapid assessment of neural conduction in explanted peripheral nerve fibers. Nat. Commun. 9, 4403 (2018).

12. Jakešová, $\mathrm{M}$. et al. Optoelectronic control of single cells using organic photocapacitors. Sci. Adv. 5, eaav5265 (2019).

13. Abdullaeva, O. S. et al. Organic photovoltaic sensors for photocapacitive stimulation of voltage-gated ion channels in neuroblastoma cells. Adv. Funct. Mater. https://doi.org/10.1002/adfm.201805177 (2018)

14. Ferlauto, L. et al. Design and validation of a foldable and photovoltaic widefield epiretinal prosthesis. Nat. Commun. 9, 992 (2018). 
15. Maya-Vetencourt, J. F. et al. A fully organic retinal prosthesis restores vision in a rat model of degenerative blindness. Nat. Mater. 16, 681-689 (2017).

16. Gautam, V., Rand, D., Hanein, Y. \& Narayan, K. A polymer optoelectronic interface provides visual cues to a blind retina. Adv. Mater. 26, 1751-1756 (2014).

17. Ghezzi, D. Retinal prostheses: progress toward the next generation implants. Front. Neurosci. 9, 290 (2015).

18. Antognazza, M. et al. Characterization of a polymer-based, fully organic prosthesis for implantation into the subretinal space of the rat. Adv. Healthcare Mater. 5, 2271-2282 (2016).

19. Di Paolo, M. et al. Inflammatory and morphological characterization of a foreign body retinal response. Eur. J. Neurodegener. Dis. 4, 23-28 (2015).

20. Bowmaker, J. \& Dartnall, H. Visual pigments of rods and cones in a human retina. J. Physiol. 298, 501-511 (1980).

21. Delori, F. C., Webb, R. H., Sliney, D. H. \& Institute, A. Maximum permissible exposures for ocular safety (ANSI 2000), with emphasis on ophthalmic devices. J. Opt. Soc. Am. A Opt. Image Sci. Vis. 24, 1250-1265 (2007).

22. Grancini, G. et al. Hot exciton dissociation in polymer solar cells. Nat. Mater. 12, 29-33 (2012)

23. Håkansson, A. et al. Effect of (3-glycidyloxypropyl)trimethoxysilane (GOPS) on the electrical properties of PEDOT:PSS films. J. Polym. Sci. Part B: Polym. Phys. 55, 814-820 (2017)

24. ElMahmoudy, M. et al. Tailoring the electrochemical and mechanical properties of PEDOT:PSS films for bioelectronics. Macromol. Mater. Eng. 302, 1600497 (2017).

25. Kim, W. et al. Comparative Study of the mechanical properties of all-polymer and fullerene-polymer solar cells: the importance of polymer acceptors for high fracture resistance. Chem. Mater. 30, 2102-2111 (2018).

26. Gargini, C., Terzibasi, E., Mazzoni, F. \& Strettoi, E. Retinal organization in the retinal degeneration 10 (rd10) mutant mouse: a morphological and ERG study. J. Comp. Neurol. 500, 222-238 (2007).

27. Pennesi, M. E. et al. Long-term characterization of retinal degeneration in rd1 and rd10 mice using spectral domain optical coherence tomography. Invest. Ophthalmol. Vis. Sci. 53, 4644-4656 (2012).

28. Margolis, D. J. \& Detwiler, P. B. Cellular origin of spontaneous ganglion cell spike activity in animal models of retinitis pigmentosa. J. Ophthalmol. 2011, 507037 (2011).

29. Chenais, N. A. L., Leccardi, M. J. I. A. \& Ghezzi, D. Capacitive-like photovoltaic epiretinal stimulation enhances and narrows the networkmediated activity of retinal ganglion cells by recruiting the lateral inhibitory network. J. Neural Eng. 16, 066009 (2019).

30. Dagnelie, G. et al. Performance of real-world functional vision tasks by blind subjects improves after implantation with the Argus ${ }^{\circledR}$ II retinal prosthesis system. Clin. Exp. Ophthalmol. 45, 152-159 (2017).

31. Zrenner, E. et al. Subretinal electronic chips allow blind patients to read letters and combine them to words. Proc. Biol. Sci. 278, 1489-1497 (2011).

32. Stingl, K. et al. Artificial vision with wirelessly powered subretinal electronic implant alpha-IMS. Proc. Biol. Sci. 280, 20130077 (2013).

33. Dorn, J. D. et al. The detection of motion by blind subjects with the epiretinal 60-electrode (Argus II) retinal prosthesis. JAMA Ophthalmol 131, 183 (2013).

34. Pérez Fornos, A. et al. Temporal properties of visual perception on electrical stimulation of the retina. Invest. Ophthalmol. Vis. Sci. 53, 2720 (2012).

35. Stronks, H. C., Barry, M. P. \& Dagnelie, G. Electrically elicited visual evoked potentials in Argus II retinal implant wearers. Invest. Ophthalmol. Vis. Sci. 54, 3891 (2013).

36. Freeman, D. Electric stimulation with sinusoids and white noise for neural prostheses. Front. Neurosci. https://doi.org/10.3389/neuro.20.001.2010 (2010)

37. Rathbun, D. L., Ghorbani, N., Shabani, H., Zrenner, E. \& Hosseinzadeh, Z. Spike-triggered average electrical stimuli as input filters for bionic vision-a perspective. J. Neural Eng. 15, 063002 (2018)

38. Lorach, H. et al. Photovoltaic restoration of sight with high visual acuity. Nature medicine 21, 476-482 (2015)

39. Mandel, Y. et al. Cortical responses elicited by photovoltaic subretinal prostheses exhibit similarities to visually evoked potentials. Nat. Commun. 4, 1980 (2013).

40. Mathieson, K. et al. Photovoltaic retinal prosthesis with high pixel density. Nat. Photonics 6, 391-397 (2012).

41. Rand, D. et al. Direct electrical neurostimulation with organic pigment photocapacitors. Adv. Mater. 30, 1707292 (2018).

42. Simone, G. et al. Near-infrared tandem organic photodiodes for future application in artificial retinal implants. Adv. Mater. 30, el 1804678 (2018).

43. Lorach, $\mathrm{H}$. et al. Retinal safety of near infrared radiation in photovoltaic restoration of sight. Biomedical Opt. Express 7, 13-21 (2016).

44. Arscott, S. et al. Terahertz time-domain spectroscopy of films fabricated from SU-8. Electron. Lett. 35, 243 (1999).

45. Markos, C., Vlachos, K. \& Kakarantzas, G. Guiding and thermal properties of a hybrid polymer-infused photonic crystal fiber. Opt. Mater. Express 2, 929 (2012).

46. Erickson, D., Sinton, D. \& Li, D. Joule heating and heat transfer in poly (dimethylsiloxane) microfluidic systems. Lab Chip 3, 141 (2003).
47. Gasiorowski, J., Menon, R., Hingerl, K., Dachev, M. \& Sariciftci, N. S. Surface morphology, optical properties and conductivity changes of poly $(3,4-$ ethylenedioxythiophene):poly(styrenesulfonate) by using additives. Thin Solid Films 536, 211-215 (2013).

48. Gosalia, K., Weiland, J., Humayun, M. \& Lazzi, G. Thermal elevation in the human eye and head due to the operation of a retinal prosthesis. IEEE Trans. Biomed. Eng. 51, 1469-1477 (2004).

49. Mirnezami, S. A., Rajaei Jafarabadi, M. \& Abrishami, M. Temperature distribution simulation of the human eye exposed to laser radiation. J. Lasers Med. Sci. 4, 175-181 (2013).

50. Vuylsteke, M., Van Dorpe, J., Roelens, J., De Bo, T. \& Mordon, S. Endovenous laser treatment: a morphological study in an animal model. Phlebology 24, 166-175 (2009).

51. van den Berg, T. J. T. P. \& Spekreijse, H. Near infrared light absorption in the human eye media. Vis. Res. 37, 249-253 (1997).

52. Hammer, M., Roggan, A., Schweitzer, D. \& Müller, G. Optical properties of ocular fundus tissues-an in vitro study using the double-integrating-sphere technique and inverse Monte Carlo simulation. Phys. Med. Biol. 40, 963-978 (1995).

53. Matsui, G. \& Kato, H. Analysis of thermal diffusivity of Ti thin film by thermoreflectance and periodic heating technique. Rev. Sci. Instrum. 82, 034905 (2011)

54. Fan, Z. \& Ouyang, J. Thermoelectric properties of PEDOT:PSS. Adv. Electron. Mater. 5, 1800769 (2019)

55. Chen, $\mathrm{H}$. et al. The role of fullerene mixing behavior in the performance of organic photovoltaics: PCBM in low-bandgap polymers. Adv. Funct. Mater. 24, 140-150 (2014).

56. Henager, C. H. Jr. \& Pawlewicz, W. T. Thermal conductivities of thin, sputtered optical films. Appl. Opt. 32, 91-101. https://doi.org/10.1364/ AO.32.000091 (1993).

57. Johnson, P. \& Christy, R. Optical constants of transition metals: Ti, V, Cr, Mn, Fe, Co, Ni, and Pd. Phys. Rev. B 9, 5056-5070 (1974).

58. Emmott, C. J. M. et al. Organic photovoltaic greenhouses: a unique application for semi-transparent PV? Energy Environ. Sci. 8, 1317-1328 (2015).

59. Guo, Z. et al. Tuning the thermal conductivity of solar cell polymers through side chain engineering. Phys. Chem. Chem. Phys. 16, 7764-7771 (2014).

60. Mark, J. E. Polymer Data Handbook. (Oxford University Press, 2009).

61. Guerin, L. J., Bossel, M., Demierre, M., Calmes, S. \& Renaud, P. Simple and low cost fabrication of embedded micro-channels by using a new thick-film photoplastic. in Proceedings of International Solid State Sensors and Actuators Conference (Transducers'97) 2 1419-1422 (IEEE, 1997).

62. Chen, C.-W. et al. Optical properties of organometal halide perovskite thin films and general device structure design rules for perovskite single and tandem solar cells. J. Mater. Chem. A 3, 9152-9159 (2015).

\section{Acknowledgements}

We would like to acknowledge the EPFL Center of Micronanotechnology and The Neural Microsystems Platform at the Wyss Center for Bio and Neuroengineering for their support. We also acknowledge Prof. Kevin Sivula and Dr. Nestor Guijarro Carratala of EPFL for the support with the UV-Vis spectroscopy measurements. This work was supported by École polytechnique fédérale de Lausanne, Medtronic, European Commission (Project 701632), Fondation Mercier pour la science, Velux Stiftung (Project 1102), Gebert Rüf Stiftung (Project GRS-035/17), the Wyss Center for Bio and Neuroengineering, and Swiss National Science Foundation (Project CR23I2-162828).

\section{Author contributions}

M.J.I.A.L. fabricated the samples and devices, recorded the photo-voltage and the photocurrent, measured the thickness and resistance, performed the soaking experiments, and performed the thermal simulations. N.A.L.C. performed ex vivo electrophysiology. L.F. fabricated the samples and performed the absorbance measurements. M.K. performed time-of-flight secondary ion mass spectrometry measurements. E.G.Z. performed in vitro cytotoxicity. D.G. supervised the entire study and wrote the paper. All the authors read and accepted the paper.

\section{Competing interests}

The authors declare that they have no competing interests.

\section{Additional information}

Supplementary information is available for this paper at https://doi.org/10.1038/s43246020-0023-4

Correspondence and requests for materials should be addressed to D.G.

Reprints and permission information is available at http://www.nature.com/reprints

Publisher's note Springer Nature remains neutral with regard to jurisdictional claims in published maps and institutional affiliations. 
(c) (i) Open Access This article is licensed under a Creative Commons Attribution 4.0 International License, which permits use, sharing, adaptation, distribution and reproduction in any medium or format, as long as you give appropriate credit to the original author(s) and the source, provide a link to the Creative Commons license, and indicate if changes were made. The images or other third party material in this article are included in the article's Creative Commons license, unless indicated otherwise in a credit line to the material. If material is not included in the article's Creative Commons license and your intended use is not permitted by statutory regulation or exceeds the permitted use, you will need to obtain permission directly from the copyright holder. To view a copy of this license, visit http://creativecommons.org/ licenses/by/4.0/.

(C) The Author(s) 2020 